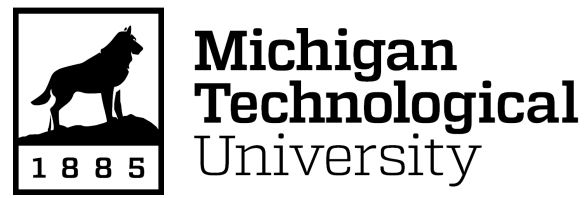

Michigan Technological University Digital Commons @ Michigan Tech

Dissertations, Master's Theses and Master's Reports

2017

\title{
MUSICAL EXERCISE FOR PEOPLE WITH VISUAL IMPAIRMENTS
}

Ridwan Ahmed Khan

Michigan Technological University, ridwank@mtu.edu

Copyright 2017 Ridwan Ahmed Khan

\section{Recommended Citation}

Khan, Ridwan Ahmed, "MUSICAL EXERCISE FOR PEOPLE WITH VISUAL IMPAIRMENTS", Open Access Master's Thesis, Michigan Technological University, 2017.

https://doi.org/10.37099/mtu.dc.etdr/513

Follow this and additional works at: https://digitalcommons.mtu.edu/etdr

Part of the Graphics and Human Computer Interfaces Commons, and the Other Computer Sciences Commons 
MUSICAL EXERCISE FOR PEOPLE WITH VISUAL IMPAIRMENTS

By

Ridwan Ahmed Khan

\begin{abstract}
A THESIS
Submitted in partial fulfillment of the requirements for the degree of MASTER OF SCIENCE

In Computer Science
\end{abstract}

MICHIGAN TECHNOLOGICAL UNIVERSITY

2017

(C) 2017 Ridwan Ahmed Khan 
This thesis has been approved in partial fulfillment of the requirements for the Degree of MASTER OF SCIENCE in Computer Science.

Department of Computer Science

Thesis Advisor: Dr. Myounghoon Jeon

Committee Member: $\quad$ Dr. Scott A Kuhl

Committee Member: Dr. Keith Vertanen

Department Chair: Dr. Min Song 


\section{Table of Contents}

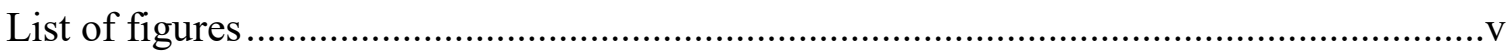

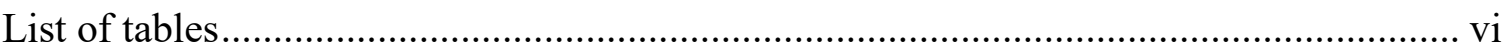

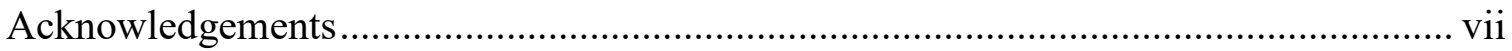

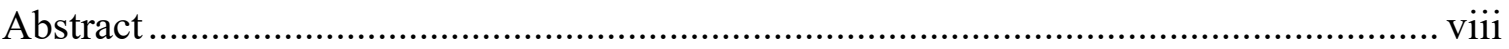

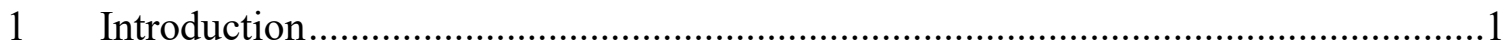

2 Background and Related Works .......................................................................2

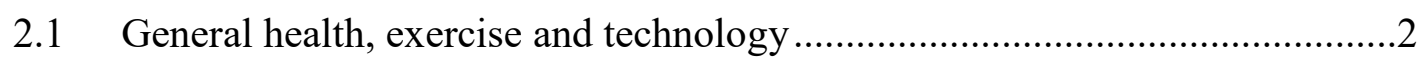

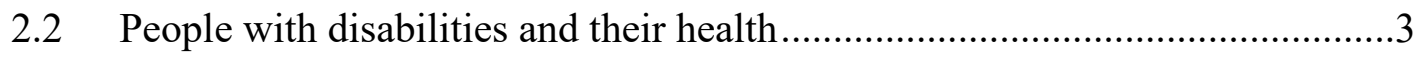

2.3 Technological assistance for people with visual impairments ..........................

3 Musical Exercise for People with Visual Impairments.............................................6

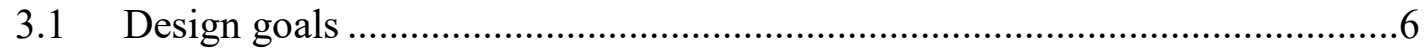

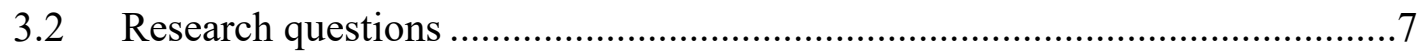

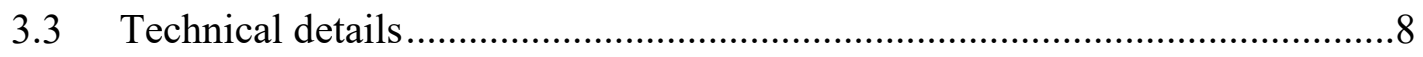

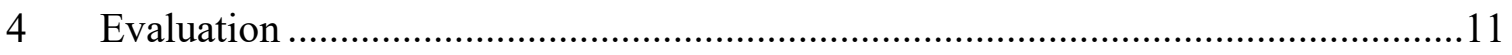

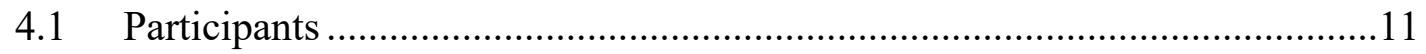

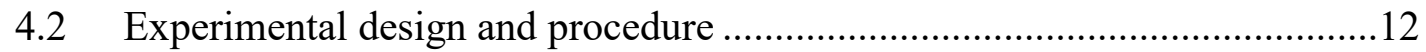

4.2.1 Experimental Conditions …………………….................................12

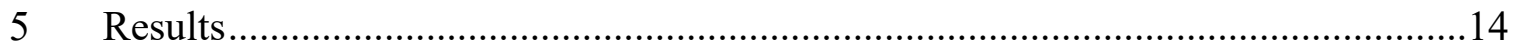

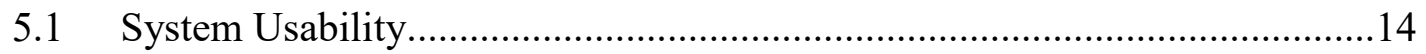

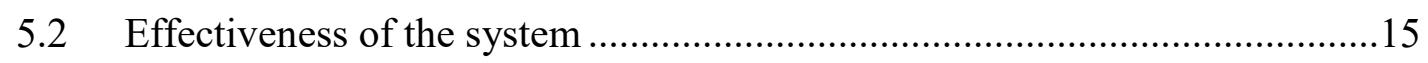

5.2.1 Effects on consistency................................................................16

5.2.2 Effects on completion time ........................................................23

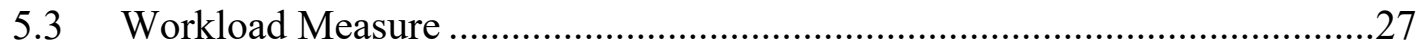

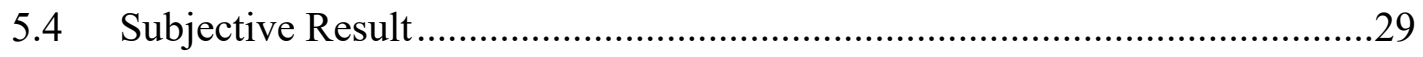

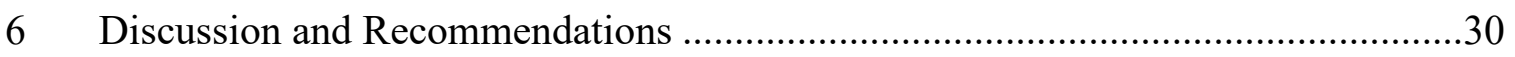

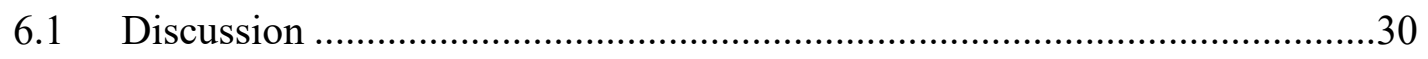

6.2 Recommendations for the future systems ....................................................31 


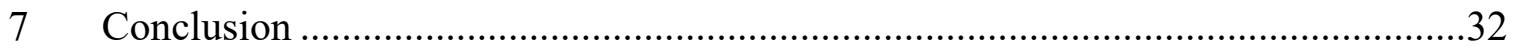

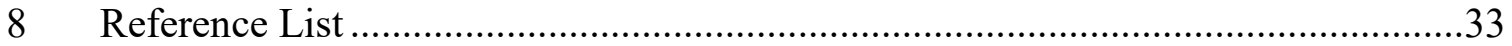

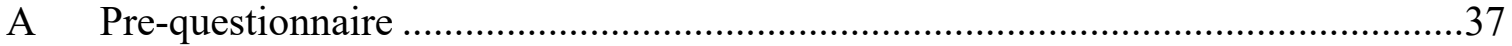

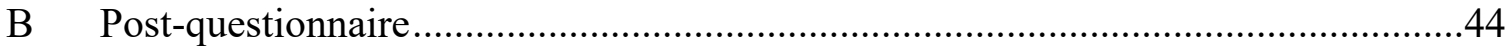

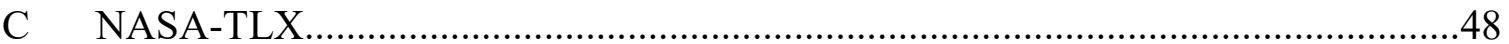




\section{List of figures}

Figure 3.1: Microsoft Kinect Device .....................................................................

Figure 3.2: From left to right, movement of the exercise ..........................................

Figure 5.1: Distance between the knee joints and the hip joints..................................15

Figure 5.2: Mean of variance in six experimental conditions for squat exercise .............16

Figure 5.3: Mean of variance in six experimental conditions for wall sit exercise ..........19

Figure 5.4: Mean distance values in six experimental conditions for squat exercise ........21

Figure 5.5: Mean distance values in six experimental conditions for wall sit exercise.....23 


\section{List of tables}

Table 5.1: Variance data for squat exercise in six experimental conditions.......................17

Table 5.2: Variance data for wall sit in six experimental conditions..................................18

Table 5.3: Average data for squat exercise in six experimental conditions........................20

Table 5.4: t-test: Two samples (Visual without audio condition vs blindfolded with discrete audio condition) based on squat exercise ................................................21

Table 5.5: Average data for wall sit exercise in six experimental conditions ...................22

Table 5.6: t-test: Two samples (Visual without audio condition vs blindfolded with discrete audio condition) based on wall sit exercise ............................................23

Table 5.7: Completion time for squat exercise ……………………………………....24

Table 5.8: t-test: Two samples (Visual without audio condition vs blindfolded with continuous audio condition) based on squat exercise ...........................................25

Table 5.9: t-test: Two samples (Visual without audio condition vs blindfolded with

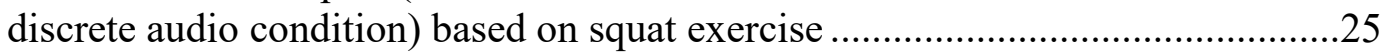

Table 5.10: Completion time for wall sit exercise ..........................................................26

Table 5.11: t-test: Two samples (Visual without audio condition vs blindfolded with continuous audio condition) based on wall sit exercise

Table 5.12: t-test: Two samples (Visual without audio condition vs blindfolded with discrete audio condition) based on wall sit exercise ............................................27

Table 5.13: Overall rating score of NASA-TLX for six experimental conditions .............28

Table 5.14: t-test: Two samples (Visual without audio condition vs blindfolded with continuous audio condition) based on overall rating score of NASA-TLX ..........28

Table 5.15: t-test: Two samples (Visual without audio condition vs blindfolded with discrete audio condition) based on overall rating score of NASA-TLX ...............29

Table 5.16: Post questionnaire Answers Score ...............................................................29 


\section{Acknowledgements}

I would like to thank all those who have helped me learn, understand and appreciate Human and Computer Interaction. I would like to thank all my professors specially my adviser Dr. Myounghoon Jeon from whom I have learned a great deal not only about the research, but also some valuable life lessons. I would like to acknowledge Dr. Tejin Yoon, without his idea and suggestion this project would seem impossible. Lastly, but not the least, I would like to thank thesis committee members- Dr. Scott Kuhl and Dr. Keith Vertanen for their support. 


\section{Abstract}

Performing independent physical exercise is critical to maintain one's good health. However, it is hard specifically for people with visual impairments to do exercise without proper guidance. They have accessibility issues and thus, without others' help, they cannot be sure if they are doing exercise in a consistent form. To address this problem, I have developed a Musical Exercise platform for people with visual impairments. With the help of audio feedback of Musical Exercise, people with visual impairments can perform exercises in a good form consistently. To assess usability of the system and compare different audio profiles of the system, I designed six different conditions, including blindfolded or visual without audio conditions, and blindfolded or visual with two different types of audio feedback (discrete vs. continuous) conditions. Eighteen sighted participants participated in the experiment, by doing two exercises - wall sit and squat with all six conditions. The System Usability Scale results show that Musical Exercise is a usable exercise assistance system without any adverse effect on exercise completion time or perceived workload (NASA-TLX). Also, the results confirm that with a specific sound design (i.e., discrete), blindfolded sighted people can do exercise as consistently as sighted people. This implies that not all sounds equally work and thus, care is required to refine auditory displays considering users, tasks, and environments. Potentials and limitations of Musical Exercise and future works are discussed with the results. 


\section{Introduction}

Physical activity or exercise is necessary for maintaining good health both physically [8] and mentally [24]. Physical activity or exercise can be of different forms. A few examples include running, swimming, bodyweight exercise, strength training, various forms of cardio exercises, or even simple walking or standing. Though physical activity or exercise is proven to be good for health, accessibility to exercise is an issue for population with disabilities [30]. People with visual impairments are part of them. They suffer from health-related issues due to lack of exercise [25] [2] [12]. The problem lies in accessibility to exercises [19]. They need active guidance from another person to help them learn and practice the exercise [25]. Even if they learn the exercise with the help of another person, they have to do it by themselves. In such a case, guidance or at least a feedback system telling them if they are doing the exercise correctly may help improve their exercises. Technological interventions can assist people with visual impairments doing the exercise [23]. However, designing an intuitive feedback system to ensure that the user does the exercise correctly and consistently is a difficult goal to achieve. The feedback system should be intuitive and real-time so that people with visual impairments can easily understand how they are doing while exercising. Also, the feedback system needs to be non-visual but clear enough at the same time. The feedback system also needs to be enjoyable so that people with visual impairments get motivated sufficiently.

To address these issues, I have designed a Musical Exercise system. It is a non- wearable exercise detection system using Microsoft Kinect which uses sound as real-time feedback. The Microsoft Kinect device is placed in front of the user and it tracks the movement of the user's joints. Musical Exercise then analyzes the movement data and decides whether it is a valid exercise. At the same time, Musical Exercise provides sound feedback which conveys the information of how the user is doing in the exercise. For the first implementation, we have selected two exercises - squat and wall sit for the experiment and designed two different audio profiles - continuous sound and discrete sound to test the Musical Exercise system.

In this thesis, I described Musical Exercise with the sound feedback system design. Then, I conducted an evaluation experiment of the system with 18 sighted participants. The results of the experiment show that Musical Exercise can have potential benefit to people with visual impairments with a proper sound design. The results also indicate that sighted people can also benefit from the Musical Exercise system with intuitive non-obtrusive sound feedback. 


\section{Background and Related Works}

Exercise is good for health. The person who does exercises regularly can enjoy a healthy life. However, people with visual impairments have accessibility issues when it comes to exercise. There are technological advancements in a health area and also there are some assistive technologies for differently abled people to do exercise or do physiotherapy for good health or rehabilitation. However, developing technological assistance in an intuitive way is scarce for people with visual impairments.

\subsection{General health, exercise and technology}

Physical activity or exercise has immense benefits. Warbutton et al. [29] reported that physical activity leads to healthier life and works as a preventive measure against many chronic diseases and premature death. They also noted that with the introduction of physical activity previously sedentary people can enjoy good health with low risk rate of diseases. Regular physical activity is also necessary for older adults. Taylor [27] pointed out the importance of physical activity for older adults. The author also explained the government issued guideline of physical activity for older adults and indicated that physical activity reduces the risk of chronic diseases in older adults. There are many traditional ways to do exercise. For example, someone likes to play sports such as basketball, football; someone likes to run or swim; someone likes to do exercise at home; someone does exercise at gym; and someone just walks. Moreover, to help with physical activity or exercise, a number of applications have been developed in recent years. These applications seem helpful in motivating people to do exercise. Gowin et al. [11] conducted a study among college students and found out that different fitness applications changed their behaviors and instilled exercising habit in their daily lives. The number of such applications is also huge [18].

Besides fitness applications, there are other devices that can be used in assistance of different physical activities or exercises. Microsoft Kinect is one of the most frequently used devices. PaperDude [4] is a game which utilizes Microsoft Kinect, in which the player will mount on a real fixed bike, paddle it and deliver newspapers from door to door in the virtual world. The fixed cycle has a power trainer which records the speed and Kinect is used to detect the hand movements for throwing the newspaper. The user wears an Oculus Rift VR to see the virtual world where he/she has to deliver newspaper. In the process of the game, the user gets cycling exercise in an entertaining and challenging way. An application named MOPET [5] uses a GPS sensor of smartphone and tracks a user's running in a fitness trail. The application has a virtual character which shows the user how to do the exercise with 3D animation which can motivate them to do the exercise. Conner and Poor [6] developed a Kinect application which corrects the exercise form of the users. The authors chose squat as an exercise and based on four rules for squat they showed visual feedback of what is right and wrong in the exercise to the user. After doing the squat exercise, the user was shown a result page where the information about exercise is shown. Wang et al. [28] developed a Kinect-based system which tracks 
a correct posture of sit to stand exercise and gives necessary auditory feedback. Their system tracks a body pose and head position and tries to correct the form of sit to stand through auditory feedback. Newbold et al. [21] designed a mechanism by which users can be musically informed of their position in the stretching exercises. This musical auditory information prevents the users from over stretching. Also, it helps the users do the exercise in an intuitive way.

\subsection{People with disabilities and their health}

There are some research studies on how to make the exercise easy for people with disabilities. A study [22] used Kinect by combining the aspect of virtual reality and natural user interfaces in a game for patients having Parkinsons Disease (PD). The patients used the developed system for motor rehabilitation exercises by playing the game. In the field study with patients, they found improvements in condition of the patients. Another study [10] also used a Kinect-based game for people who have to use wheel chairs. The authors developed a game that required the full body motion while sitting in a wheel chair to play the game. This game can be used for people who cannot walk to support their physical exercise to some extent. In a similar research study [17], Kinect was used for rehabilitation purpose for patients' movement disorders. The authors used Tai Chi movement as the exercise for the patients. They proposed an exercise program in which patients can be rated on how well they have done in the list of exercises. This system provides a way for the patients with movement disabilities to do their exercises in an interactive way. Another research [9] also used a Kinect-based system for older adults to motivate them to exercise. The authors built a prototype system where they have arm raising to touch a point virtually as an exercise. They experimented with their prototype system and found out that integrating social network features and more visual animations in the system can motivate people to do exercise. Another system [13] worked as a game to aid upper extremities rehabilitation developed by Huang et al. The authors used a wearable glove and Kinect to play a game which can help patients to improve their upper extremities rehabilitation exercises. Another research [1] used Nintendo Wii Balance Board to play a game which can be helpful for patients with Parkinsons Disease. This system incorporated a game which can be played by the patients using the Wii board keeping their balance in both sitting and standing positions. This training system works as balance rehabilitation exercise for patients with Parkinsons Disease.

Another interesting study [14] showed that multimodal feedback can be helpful to older adults for performance gain while doing an activity. A system with auditory feedback was developed by Singh et al. [26] to support exercise for people with chronic pain. The researchers found that when the audio was tailored to one's personality, then the exercise became psychologically motivating. 


\subsection{Technological assistance for people with visual impairments}

Assistive technologies can help people with visual impairments do exercises or physical activity easily. One such a project is Gobi [20], which helps swimmers with visual impairments to stay on the right way while swimming. It is a wearable device on the thigh which tracks the swimming lane with a camera and guides the swimmers to swim left or right if they are swimming away. It also informs the swimmers of their continuation of the right path and if there is a wall ahead. Winoto and Tang [31] developed a helmet attached Arduino and speakers for people with visual impairments to play games or move around. After the users wear the helmet which has five directional speakers, the system generates sound via one of the speakers and if the user follows that direction, then the user gets haptic feedback as vibration via a mobile phone. This application can be used to guide people with visual impairments to play mobile games. Al Zayer et al. [32] explored the idea of using an aerial quadrotor to guide a blind runner in running. The authors built a prototype which tracks the runner using a marker on the shirt of the runner and the quadrotor flies above the runner to guide. Morelli et al. [19] designed an exercise game for people with visual impairments which is similar to a popular tennis game for sighted people. In the original version of the game for sighted people, visual feedback was the primary feedback system and audio was the secondary feedback system. In the system developed for people with visual impairments by the researchers, the primary feedback was replaced with tactile feedback and audio remained as the secondary feedback. The Visually Impaired Tennis game was developed for the Wii platform to help users with visual impairments to create a cognitive model of the game play and then interactively playing the game with the feedback system. Rector et al. [23] used a Kinect device to help people with visual impairments doing yoga exercises. The researchers designed the project for people with visual impairments with an auditory feedback system. In the system, speech instructions were given for a specific yoga pose. Using Kinect, the system tracks the users' body and limb positions and provides instructional audio.

As shown above, researchers so far, accommodated different feedback systems for people with visual impairments. Tactile or haptic feedback system is common, but using this type of feedback system comes with some caveats, e.g., most of the time, the tactile or haptic device needs to be placed on users' body which seems obtrusive. Sometimes, it may distract the users because they have physical responses from these devices. On the other hand, some researchers used audio feedback to convey information about the activity or the exercise. For example, Rector et al. [23] used speech instructions to guide users to their correct poses. It is a non-obtrusive approach and users can hear the instructions and follow. However, speech instructions can be limited in number as these instructions are pre-recorded and not real-time and may not meet the requirement of instructing of every possible case the users can find themselves in. Also, another aspect of speech instruction is that sometimes it provides a type of abstract information; e.g., if the system says "move your right hand", the distance to move the right hand may be different for different users. Therefore, instructional speech may not cater to the specific 
need of a specific user. Musical Exercise aims to address these issues. It also tracks a user's movements and provides audio feedback which is non-obtrusive and real-time. What differentiates Musical Exercise from other audio feedback-based systems is that it uses non-speech audio or musical notes. The benefit of using musical notes is that it can cater to the need of specific users. Users learn to hear the collection of musical notes of a proper form of the exercise. When they are deviating from the proper form, instantly the notes sound different. The sound of one user's proper form differentiates from another user. In that way, Musical Exercise addresses the issue of giving individualized feedback elaborating non-speech sound which is not confined by speech sounds. 


\section{Musical Exercise for People with Visual Impairments}

In this section, I discuss the objectives of Musical Exercise for people with visual impairments, research questions, and hypotheses. How Musical Exercise project was developed and what technologies were used are also delineated.

\subsection{Design goals}

People with visual impairments may face problems e.g., accessibility when they want to do exercise [19] [25]. To tackle this problem, I designed and developed Musical Exercise to help them do the exercise in a comfortable and effective way. I built such a system that would encourage people with visual impairments do exercise at home enjoyably and get feedback about how they are doing their exercises. Below is the list of main design goals:

a) Motivate to do exercise: Musical Exercise was designed to motivate people to exercise. With this system, people listen to the music of their body movement. Music can create positive affect in this situation [16]. Thus, by doing exercise which creates the music, people may become more interactive and engaged to the task. An engaging and interactive task creates motivation in people. One of the goals with Musical Exercise was to use motivation to keep people regularly do the exercise.

b) Learn exercise: Another design goal of Musical Exercise is to make it simple and easily accessible for people with visual impairments to learn different exercises. Once people are introduced to the system and the exercises, they can start learning about those exercises by themselves. The sound of Musical Exercise works as a guidance which provides them clear feedback of how they are doing in the exercise. They can learn how to do the exercise and what is the most comfortable way to do the exercise correctly. As novices, people start learning about exercises, they can use this system and progress in their learning of exercise quickly.

c) Guide to do exercise: After learning the exercise using Musical Exercise, people can continue using the system as their guidance system while doing exercise. People learned a proper form of exercise and how to perform the exercise during their learning process. Then, when they do exercise, they will try to follow the proper form of the exercise. Musical Exercise will give people with visual impairments sound feedback so that they can simulate the sound of the proper form of that exercise. The sound intuitively guides them to maintain the proper form of the exercise and do the exercise in a correct and effective way.

d) Perform the exercise as good as a sighted person: One of the motivations behind Musical Exercise was to enable people with visual impairments to do the exercise as good as a sighted person can do. Musical Exercise utilizes Microsoft Kinect to track motions of the user and then uses the tracking data to assist the user perform efficiently through sound feedback. Sound or music is an intuitive way of feedback and instigates more physical responses from the user [7]. Also, sound is a non-intrusive feedback 
system for people with visual impairments. Therefore, people with visual impairments can do exercise as well enough as a sighted person using the Musical Exercise system.

e) Reliance on assistive technology at home: Musical Exercise aims to support people with visual impairments to do exercise with assistive feedback in the form of sound. People with visual impairments do not need to go to the gym or take any help from any other people. They can use the system and do exercise. They can get auditory feedback from the system which helps them realize how well they are doing the exercise. Less assistance is needed to guide the exercise session. More importantly, people with visual impairments can use Musical Exercise at their home at their convenient time. They are getting technical assistance from Musical Exercise to perform the exercise at their homes.

\subsection{Research questions}

Based on the objectives of Musical exercise, I have tried to find answers to the following three research questions:

Research question 1: Can a usable exercise assistance system be built for people with visual impairments?: Musical Exercise is an exercise assistance system for people with visual impairments.

-Hypotheses 1: Musical Exercise will be rated as a usable exercise assistance system by the blindfolded participants. This question will be answered by the System Usability Scale (SUS) score.

Research questions 2: Can people with visual impairments do the exercise as well as a sighted person do?:

-Hypotheses 2: Musical Exercise will help people with visual impairments doing the exercise as effectively as a sighted person is doing. This question will be answered based on the effects on consistency, effects on time, and workload comparing blindfolded with audio conditions and visual without audio condition.

Research question 3: How can different sound design assist people with visual impairments to do exercise differently?: Musical Exercise has two distinct audio profiles. The first question is whether adding sound to the system is potentially helpful, which will be answered by comparing the exercise form consistency during blindfolded with audio conditions and visual without audio condition. Also, the effects of different audio profiles will be shown based on the evaluation results.

-Hypotheses 3.a: Continuous sound will assist people with visual impairments to do the exercise equivalent to the visual without audio condition. This will be answered by comparing the effects of continuous sound on exercise. 
-Hypotheses 3.b: Discrete sound will assist people with visual impairments to do the exercise equivalent to visual without audio condition. This will also be answered by comparing the effects of discrete sound on exercise.

\subsection{Technical details}

In Musical Exercise, participants performed two exercises - squat and wall sit in front of a Microsoft Kinect device.

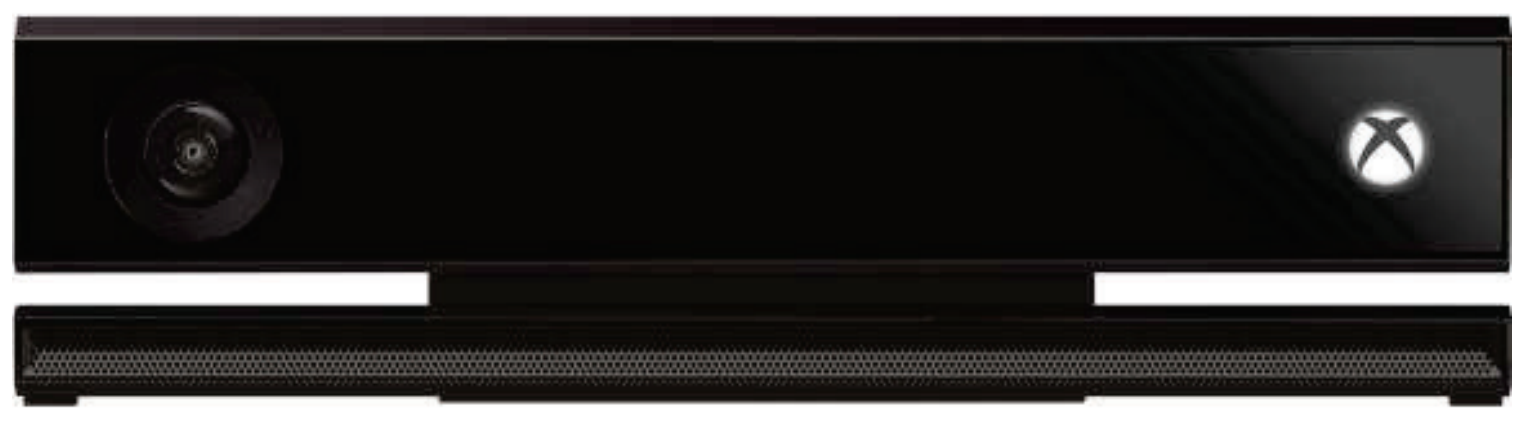

Figure 3.1: Microsoft Kinect Device

Microsoft Kinect, which is a non-wearable device, can detect the participant's body movements and Musical Exercise used the Kinect data to recognize the specific exercise movement. Kinect was placed on a desk in front of the participant. The musical exercise application measured how many repetitions the participant had done so far, how consistent these movements had been and how much time the participant had taken to complete the movement. Also, our application provided audio feedback so that the participant can understand the quality of the exercise such as when the participant had completed the full range of motion for that specific exercise. This audio-based feedback system can be especially helpful for people with visual impairments.

For the development of Musical Exercise application, Microsoft Kinect for Windows Software Development Kit(SDK) version 2.0 and C\# was used. A code template (source: http://kinect.github.io/tutorial/) was used to develop the application. The specific code template that was used to develop, was the Displaying body data template. This code template shows how to get BodyFrame from Kinect, using CoOrdinateMapper for 3D positions $(\mathrm{x}, \mathrm{y}, \mathrm{z})$ positions of different body joints and displaying the human body as a 
skeleton using the XAML figure drawing. On top of this code template, I added my algorithm for match a specific exercise - either the squat or the wall sit exercise.

The two exercises incorporate the movement which is from standing up to going down to the position when the knees are in straight line with the hip, which makes a 90 degree angle in the knee and has the thigh parallel to the ground. The exercise ends when going back to the standing position. The difference between wall sit and squat exercise is that in wall sit exercise, the person has to hold that sitting position longer and has back support of the wall. Figure 3.2 shows the movement of squat and wall sit.

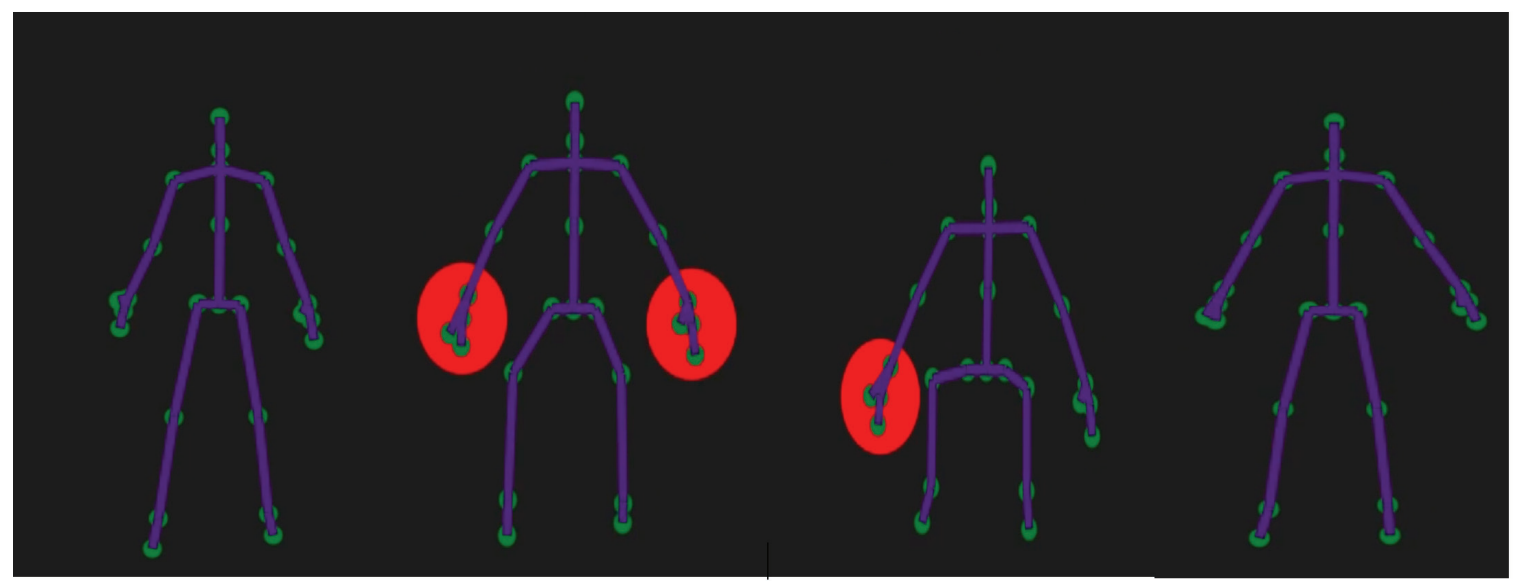

Figure 3.2: From left to right, movement of the exercise

The algorithm for matching squat or wall sit is same. In the Musical Exercise application, the input for detecting an exercise algorithm is the set of body joints. Then, body joints' coordinate values for two knee points and two hip points are saved as variables in realtime. Kinect continuously tracks the body joints, so when the distance between the hip points and the knee points decreases, the exercise is in motion. If the difference is zero or close to zero, the exercise is going to be valid and the participant stands up from that position. This is the full range motion. If the participant does not do the full range motion of an exercise, it is not detected as a successful exercise repetition. While the participant is in exercise motion, one of the two audio profiles will be played based on the participant's state in the exercise motion. The continuous audio profile has eight notes. In the full range motion of an exercise, these eight notes were set to be played based on the participant's position or state in the exercise motion. These are MIDI notes ranging from MIDI number 60 to 71 . First note is played when the distance value crosses first cut-off point (28 unit, 1 unit $=1 \mathrm{~cm}$ ). Sequentially, the notes are played when the distance value crosses than $22,16,10,7,4,2$ and less than 2 . The range of motion is not big enough to accommodate eight MIDI notes sound separately with time gaps in between. Thus, this audio profile sound like a continuous audio in practice. Hence, this audio profile is named continuous audio. For example, when the participant is going down to a sit position, eight notes $(\mathrm{B}, \mathrm{A}, \mathrm{G}, \mathrm{F}, \mathrm{E}, \mathrm{D}, \mathrm{CH}, \mathrm{C})$ are played with decreasing polarity one by one in order. 
When the participant stands up to complete the movement, the same eight notes are played in the reverse order. If the participants are familiar with at what position which note is played, they can remember the note progression or sequence and try to mimic each time they do the exercise. In short, the sound notes in the continuous audio profile specifically produce feedback on if the participant is doing the exercise in a correct form. If the participant does not do the exercise in an ideal form, then they will hear different sound compared to the sound of the ideal form of exercise. The discrete audio profile was designed in a simplistic way with three MIDI notes. It has a starting note (G\#-44) at the first cut-off points when the exercise begins, an intermediate note (E-64) when the participant is at an acceptable depth (i.e., when the distance between knee points and hip points is almost zero note), and lastly an ending note (C-84) to mark the completion. All three MIDI notes sound separately and distinguishably while the participant doing the exercise. Hence, the name of this audio profile is discrete audio. I conducted an evaluation experiment comparing these two audio profiles with participants doing both exercises.

To decide the requirements of being a valid exercise repetition, I interviewed physical exercise therapy researcher, Dr. Tejin Yoon, Assistant Professor of the Kinesiology and Integrative Physiology Department of Michigan Tech, and his student, a professional competitor in exercise competitions who regularly performs the exercises. They both suggested squat as a recommended full body exercise and wall sit as a good exercise for people. That is why these two exercises were included in the Musical Exercise. From the conversations with them, for either squat or wall sit, the full range of motion was recommended. Also, the rule of thigh of a person parallel to the ground in squat or wall sit position was indicated as a good form of that exercise [15]. They also emphasized that the consistency in exercise movement is a crucial indicator of successful exercise. Following their advice, I implemented the exercise detecting algorithm based on these rules. In the exercise detecting algorithm, two knee joints and two hip points are detected and their coordinate positions are calculated. In both exercises, the distance between knee and hip positions is calculated using these position coordinates. If the value of distance is decreasing, then a state flag variable is set to indicate that the exercise has begun. The distance value will decrease continuously as the participant is going to squat or wall sit to the point where the distance between hip joints and knee joints is zero or less. When the participant is standing up to complete the repetition of the exercise, the distance value will begin to increase. As it crosses a threshold value, the state flag variable is set to another number which states that the exercise repetition is complete. The threshold value was set to 10.0 unit (here, 1 unit means 1 centimeter in Kinect) in distance which means the participant is almost in the standing up position. This routine of detecting exercise repetition can go on for multiple repetitions. During each repetition of exercise, the time to complete the exercise from the start to finish is calculated and the lowest squat or wall sit with respect to Kinect device is calculated. 


\section{Evaluation}

In this chapter, I discuss methods of the Musical Exercise evaluation study, including participants information, experimental design and procedure.

\subsection{Participants}

Eighteen participants attended the study. Of 18 participants, 13 participants (72.22\%) were male and 5 participants $(27.78 \%)$ were female. The average age of participants is 20.05 years with a range from 19 years to 22 years old. They were all sighted participants. This study is a proof of concept in a way that if Musical Exercise can benefit blindfolded sighted people, then it may also in the same way be effective for people with visual impairments. According to Moll and Sallnäs [35], if any constraint is implied on the sighted blindfolded person, it is hoped to be applicable for people with visual impairments. Kanwal et al. [34] also showed in their experiment of a navigation assistance system, the walking speed of the blindfolded participants were less than blind people. Therefore, a system designed for people with visual impairments like Musical Exercise is likely to impose more restraints in terms of performance on a blindfolded sighted person than a person with visual impairment. All of their professions are undergraduate students at Michigan Technological University. The participants were recruited using the Sona system (Psychology Subject Recruitment System) (https://mtu.sona-systems.com/default.aspx) of Michigan Technological University. The seven questions of the general health section of the pre-questionnaire (Appendix Aquestion no. 6 to 12) was posted in the description of the present study in the Sona system. Participants were asked to answer either yes or no to the questions truthfully. These questions basically tested the physical readiness of the participant for the study. Only the participants who answered "no" to the all seven questions were allowed to take part in the exercise study. The exercise study was designed for total two hours for each participant. Each participant was compensated with four class credits for this two hour study. The study was conducted in room EERC 510 at Michigan Tech. In the prequestionnaire of the exercise study, all the participants expressed their interest to do exercise for better well-being. However, only ten people wanted to use technological assistance to do exercise and the rest eight people did not want to use technology. When asked whether they have used any fitness related applications, eight participants have used before and the rest ten participants have not used such applications before. The participants were asked if they do exercise in their lives and the kind of exercises. Only one participant was not used to do any form of exercise in their daily lives and other 17 people did exercise in various forms (e.g. yoga, bodyweight exercises, playing games, barbell or dumbbell exercise or cardio). All the participants, at least, heard about squat and wall sit exercise before. Eleven participants do squat exercise at least sometimes and 13 participants do wall sit exercise at least sometimes in their daily lives. 


\subsection{Experimental design and procedure}

After reading and signing the consent form, participants answered the pre-questionnaire (Appendix A) at the end of the consent form. This questionnaire has seven questions under the general health section which checks if the participant is physically ready for the experiment. The pre-questionnaire also asked participants their name, age, height, weight and their usual activity level. The activity level was self-reported by the participant. All participants must pass all of our exclusion criterion:

$\dagger$ Answering "no" to the seven questions of the general health section of the prequestionnaire (Appendix A- question no. 6 to 12)

$\dagger$ Having reasonable hearing capacity (self-reported)

$\dagger$ Willing to engage in moderate exercise for about 60 minutes of exercise with some rest times in between.

To give an idea on the amount of physical activity participants needed to exert for this study, a typical participant is a 22 year old person who self-reports doing 1-2 exercises a week as the activity level requires two exercises in multiple repetitions given rest times within about an hour. The rest time varied around 2-3 minutes or as the participant wishes. The seven questions of the general health section of the pre-questionnaire (Appendix A-question no. 6 to 12) would disqualify those identified to run a higher risk for complications during exercise. In the evaluation study, no participant was disqualified. Participants were asked to complete two exercises five times in each set of two sets with given the rest time between a set of repetitions under the different experimental conditions in random order. The detailed description of these experimental conditions is given in the below subsection. After completing each experimental condition, the participants were asked to answer the NASA-TLX workload measurement questions using an online tool (source: https://www.keithv.com/software/nasatlx/). When all the experimental conditions were completed, the participants were asked for any feedback, questions, or comments on the efficacy and preference of the system in a post questionnaire form. The post questionnaire form included System Usability Scale questions and questions on quality of the system and its audio component, and if the system is intuitive or has enough information for doing the exercise, etc.

\subsubsection{Experimental Conditions}

Once the participants signed the consent form and answered the pre-questionnaire, they were briefed in short about the exercise application. The participants were then assigned to the following six conditions in random order:

$\dagger$ Visual without audio condition: The participants saw the application running in a desktop monitor in front of them. The Kinect device was at a table beside the monitor which tracked their movement. In application, the participants saw how they were 
moving. The participants were asked to perform two exercises - squat and wall sit in random order. There were two sets of each exercise. In each set, the exercise needed to be repeated five times. There was 2-3 minute rest time for the participants between the sets. The participants were not blindfolded and did not hear any audio in this condition.

$\uparrow$ Blindfolded without audio condition: Everything was same as the visual without audio condition except that the participant was blindfolded.

$\uparrow$ Visual with continuous audio condition: It was same as the visual without audio condition except that the participant heard sound according to continuous audio profile from the desktop monitor speaker. This sound included eight MIDI notes. If the participant performed the same movement, they would hear the same notes.

$\dagger$ Visual with discrete audio condition: Everything was same as the visual without audio condition except that the participant heard sound according to discrete audio profile from the desktop monitor speaker. The discrete audio profile included three MIDI notes.

$\dagger$ Blindfolded with continuous audio condition: Everything was same as the visual with continuous audio condition except that the participant was blindfolded.

$\uparrow$ Blindfolded with discrete audio condition: Everything was same as the visual with discrete audio condition except that the participant was blindfolded.

Table 4.1 shows the summary of the six experimental conditions:

\begin{tabular}{|l|l|l|}
\hline Conditions & Blindfolded & Audio \\
\hline Visual without audio & No & No \\
\hline Blindfolded without audio & Yes & No \\
\hline $\begin{array}{l}\text { Visual with continuous } \\
\text { audio }\end{array}$ & No & Continuous \\
\hline Visual with discrete audio & No & Discrete \\
\hline $\begin{array}{l}\text { Blindfolded with } \\
\text { continuous audio }\end{array}$ & Yes & Continuous \\
\hline $\begin{array}{l}\text { Blindfolded with discrete } \\
\text { audio }\end{array}$ & Yes & Discrete \\
\hline
\end{tabular}




\section{Results}

In this chapter, results from the evaluation of Musical Exercise are described. Firstly, I present how usable the Musical Exercise system is using the System Usability Scale (SUS) scores. Then, I report the effectiveness of Musical Exercise by discussing consistency of the exercise across different conditions. I also checked whether there is any effect of completion time among the conditions. After that, I show the workload measurement results across different experimental conditions. Lastly, I present a subjective review of the experimental study.

Sometimes, the reading from the Kinect device was not right; it showed a skewed figure in the display monitor and data were either lost or over counted. Having this limitation, I tried to minimize such effects by taking repetition count to five counts per session only when there is over counting of repetition problem and for the lost repetition, I included the average value of the previous repetitions. The number of count lost was 31 sessions out 672 sessions of exercise for all eighteen participants and the number of more than five count was 23 sessions out of 672 sessions of exercise.

\subsection{System Usability}

I used System Usability Scale or SUS (source: https:/www.usability.gov/how-to- andtools/methods/system-usability-scale.html) to measure the usability of our system. SUS is a set of ten questions where each question has five answer options from "Strongly disagree" to "Strongly agree" scale. The score is calculated on a total of 100 points (for details about calculation, please see here - https://measuringu.com/sus/). SUS is a reliable and effective way to measure a system's usability [3]. The procedure for collecting SUS data I followed is that after completing all the conditions, each participant answered the ten SUS questions which were included as part of the post-questionnaire (Appendix B). The researcher asked the participants to answer those questions based on their experience of the Musical Exercise system as a whole while focusing on the usability of the two blindfolded with audio conditions as the system was intended for people with visual impairments. The mean SUS score for Musical Exercise was 71.53 out of total score 100 with a standard deviation of 8.45 calculated from 18 participants' data. The maximum SUS score is 85 and the minimum is 55 among 18 participant's SUS scores. Based on the results from 500 studies, the average SUS score 68 or above 68 is considered an "above average" system (sources: https://measuringu.com/sus/ and https://www.usability.gov/how- to-and-tools/methods/system-usability-scale.html). Another study [3] reported that a SUS score of 71.4 with standard deviation of 11.6 can be described as a "good" system. Thus, from the references the Musical Exercise system stands as an "above average" or "good" usable system. 


\subsection{Effectiveness of the system}

To measure the effectiveness of Musical Exercises, first I analyzed how consistently the participants did the exercise among the six conditions by calculating the variance data of distance values calculated from the exercises. Small variance means more consistency. However, that consistency can be from a bad form of exercise. For example, even though the participants consistently did the exercise, they might not sufficiently sit to the acceptable level as a successful position. Then, it would be consistently bad exercise. On the other hand, if the participants do the exercise consistently by maintaining a proper form almost all the time, then the variance of distance values will also be low. However, in this case, this small variance would be good because the participants did the exercise constantly in the proper form. That is why, I analyzed if that consistency is bad or good by comparing average distance values between knee and hip when the participants sit in both exercises across conditions. Figure 5.1 shows the distance between knee and hip joints.

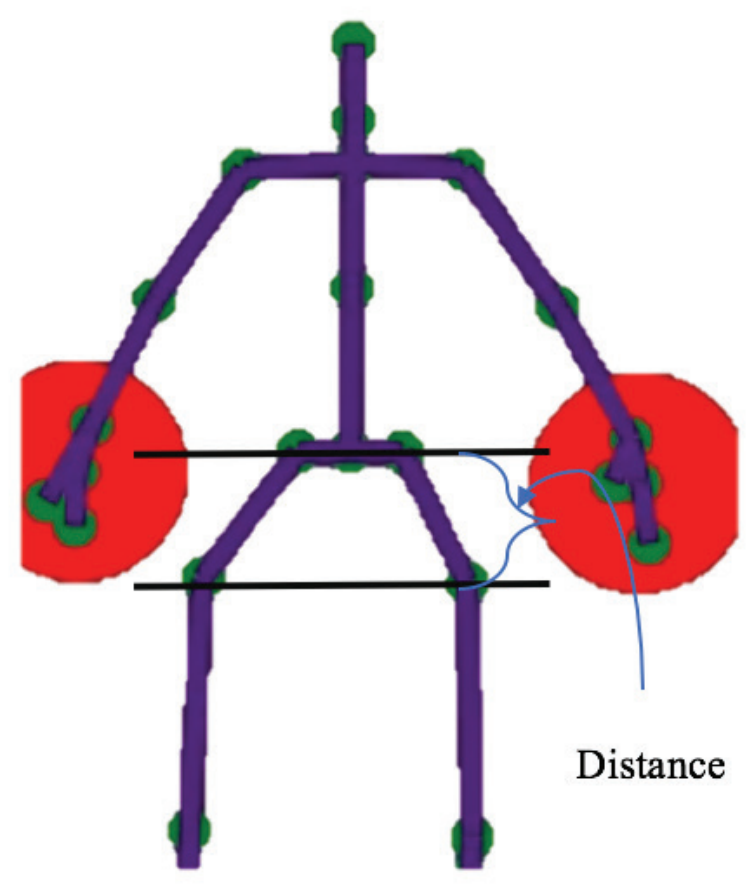

Figure 5.1: Distance between the knee joints and the hip joints

Deciding good or bad consistency needs a base condition with which I can compare the conditions in question. I selected the visual without audio condition as the baseline condition because if sighted people do not use any exercise assistance system, they would do the exercise just like in the visual without audio condition in this experiment. Therefore, I compared the average distance values of the blindfolded with audio conditions (discrete and continuous) with average distance values of the visual without audio condition after checking consistency of the conditions. Because of this reason, I directly conducted planned pairwise comparisons using paired samples t-tests, instead of 
conducting ANOVA first and then using the Bonferroni correction. Therefore, I maintained a traditional alpha level (0.05) [33]. Each average distance value represented the average of five repetitions' distance values between the knee joints and the hip joints of a participant. The description of exercise consistency is followed by the completion time analysis between conditions.

\subsubsection{Effects on consistency}

To measure the consistency of the exercise, I calculated the variance in distance between knee and hip data when participants repeated the same exercise. The distance value variance indicates how perfectly the participants did the exercise since equal or less than zero in the distance is considered a good form for both wall sit and squat exercises. Table 5.1 shows the variance data of squat exercise among six experimental conditions. From the table 5.1, I can see that the variance values of the visual with discrete audio condition and the blindfolded with discrete audio condition are the least among the six conditions if I consider total sum of variance, average variance, or even variance of variance values.

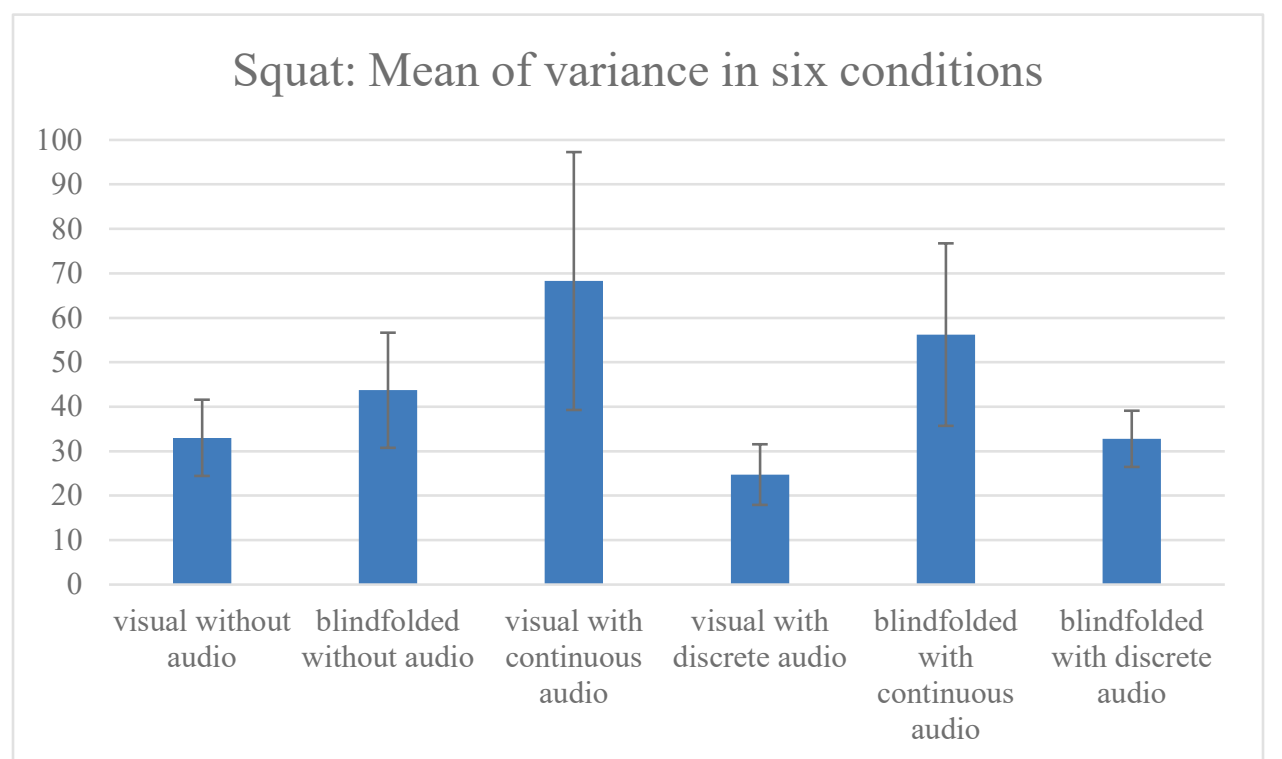

Figure 5.2: Mean of variance in six experimental conditions for squat exercise 
Table 5.1: Variance data for squat exercise in six experimental conditions

\begin{tabular}{|l|l|l|l|l|l|}
\hline Conditions & Count & Sum & Average & Variance & $\begin{array}{l}\text { Standard } \\
\text { deviation }\end{array}$ \\
\hline $\begin{array}{l}\text { Visual } \\
\text { without } \\
\text { audio }\end{array}$ & 18 & 594.159 & 33.009 & 1322.933 & 36.372 \\
\hline $\begin{array}{l}\text { Blindfolded } \\
\text { without } \\
\text { audio }\end{array}$ & 18 & 786.739 & 43.708 & 3017.291 & 54.929 \\
\hline $\begin{array}{l}\text { Visual with } \\
\text { continuous } \\
\text { audio }\end{array}$ & 18 & 1228.879 & 68.271 & 15138.509 & 123.039 \\
\hline $\begin{array}{l}\text { Visual with } \\
\text { discrete } \\
\text { audio }\end{array}$ & 18 & 18 & & & \\
\hline $\begin{array}{l}\text { Blindfolded } \\
\text { with } \\
\text { continuous } \\
\text { audio }\end{array}$ & 18 & 1012.042 & 56.225 & 7581.276 & 87.071 \\
\hline $\begin{array}{l}\text { Blindfolded } \\
\text { with } \\
\text { discrete } \\
\text { audio }\end{array}$ & 18 & 590.074 & 32.782 & 718.998 & 26.814 \\
\hline
\end{tabular}

The visual with continuous audio and the blindfolded with continuous audio conditions have the biggest variance values among the six conditions. What this implies is that with discrete audio either blindfolded or not, the participants seemed to perform squat more consistently than with the visual without audio condition or the blindfolded without audio condition. In the same way, with continuous audio either blindfolded or not, the participants seemed to perform squat more inconsistently than the visual without audio condition or the blindfolded without audio condition. 
Table 5.2: Variance data for wall sit in six experimental conditions

\begin{tabular}{|c|c|c|c|c|c|}
\hline Conditions & Count & Sum & Average & Variance & $\begin{array}{l}\text { Standard } \\
\text { deviation }\end{array}$ \\
\hline $\begin{array}{l}\text { Visual } \\
\text { without } \\
\text { audio }\end{array}$ & 18 & 457.724 & 25.429 & 801.7 & 28.314 \\
\hline $\begin{array}{l}\text { Blindfolded } \\
\text { without } \\
\text { audio }\end{array}$ & 18 & 923.243 & 51.291 & 1996.086 & 44.678 \\
\hline $\begin{array}{l}\text { Visual with } \\
\text { continuous } \\
\text { audio }\end{array}$ & 18 & 818.446 & 45.469 & 4795.157 & 69.247 \\
\hline $\begin{array}{l}\text { Visual with } \\
\text { discrete } \\
\text { audio }\end{array}$ & 18 & 517.572 & 28.754 & 749.419 & 27.376 \\
\hline $\begin{array}{l}\text { Blindfolded } \\
\text { with } \\
\text { continuous } \\
\text { audio }\end{array}$ & 18 & 1001.747 & 55.653 & 7767.746 & 88.135 \\
\hline $\begin{array}{l}\text { Blindfolded } \\
\text { with } \\
\text { discrete } \\
\text { audio }\end{array}$ & 18 & 1026.737 & 57.041 & 5564.932 & 74.598 \\
\hline
\end{tabular}




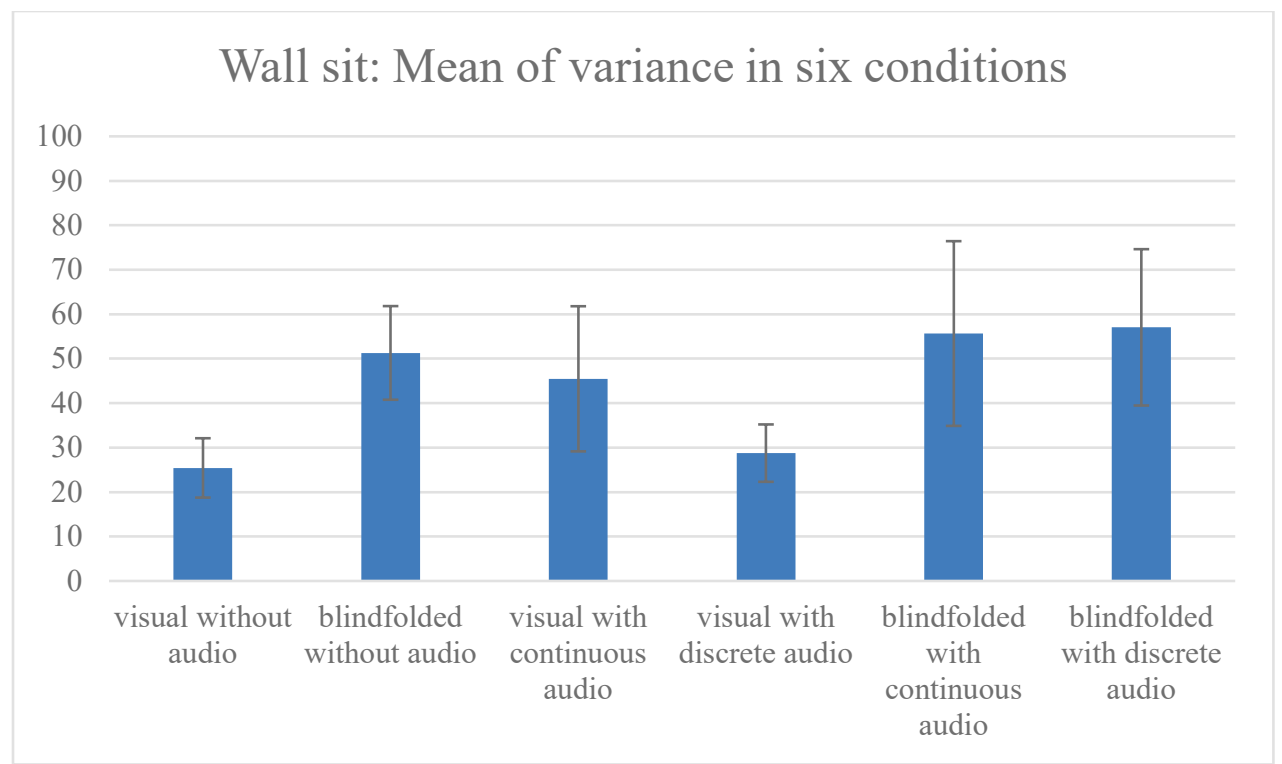

Figure 5.3: Mean of variance in six experimental conditions for wall sit exercise

For wall sit, from the table 5.2, it can be seen that the variance values of the visual with discrete audio condition is the least among the six conditions if I consider total sum of variance, average variance, or even variance of variance values. However, the same is not true for the blindfolded with discrete audio condition. The visual with continuous audio condition and the blindfolded with continuous audio condition show the biggest variance values among the six conditions. What this implies is that in the visual with discrete audio condition, the participants seemed to perform wall sit more consistently than the visual without audio condition or the blindfolded without audio condition. However, in the blindfolded with discrete audio condition the participants seemed to perform less consistently than in the blindfolded without audio condition or the visual without audio condition. In the blindfolded with continuous audio, the participants seemed to perform wall sit more inconsistently than in the visual without audio condition or the blindfolded without audio condition.

In the visual with discrete audio condition, the participants seemed to perform more consistently for both exercises. When in the blindfolded with discrete audio condition the participants performed squat more consistently than either the visual without audio condition or the blindfolded without audio condition, but it is not the same case for wall sit exercise. Next, I show whether the consistent form is a good one or bad one.

To determine if the participants performed in a consistently good form or bad form, I took the mean distance values of the exercise. Previously, while checking if the exercise is done consistently, I have found that in the visual with discrete audio condition, the participants performed more consistently. While the participants in the blindfolded with discrete audio condition performed, at least, as good as those in the visual without audio condition for squat exercise, for wall sit exercise it was not shown in the same way. It has been shown that participants in the continuous audio conditions either blindfolded or not 
did not provide much consistent results in either of the exercises. Therefore, I focus on the paired samples t-tests with visual without audio condition average data and blindfolded with only discrete audio condition average data.

First for the squat exercise, table 5.3 shows the average values and standard deviation of mean distance data.

Table 5.3: Average data for squat exercise in six experimental conditions

\begin{tabular}{|c|c|c|c|c|c|}
\hline Conditions & Count & Sum & Average & Variance & $\begin{array}{l}\text { Standard } \\
\text { Deviation }\end{array}$ \\
\hline $\begin{array}{l}\text { Visual } \\
\text { without } \\
\text { audio }\end{array}$ & 18 & -466.583 & -25.921 & 118.738 & 10.897 \\
\hline $\begin{array}{l}\text { Blindfolded } \\
\text { without } \\
\text { audio }\end{array}$ & 18 & -500.434 & -27.802 & 92.724 & 9.629 \\
\hline $\begin{array}{l}\text { Visual with } \\
\text { continuous } \\
\text { audio }\end{array}$ & 18 & -461.375 & -25.632 & 63.465 & 7.966 \\
\hline $\begin{array}{l}\text { Visual with } \\
\text { discrete } \\
\text { audio }\end{array}$ & 18 & -493.971 & -27.443 & 55.033 & 7.418 \\
\hline $\begin{array}{l}\text { Blindfolded } \\
\text { with } \\
\text { continuous } \\
\text { audio }\end{array}$ & 18 & -499.871 & -27.771 & 109.025 & 10.441 \\
\hline $\begin{array}{l}\text { Blindfolded } \\
\text { with } \\
\text { discrete } \\
\text { audio }\end{array}$ & 18 & -483.542 & -26.863 & 102.882 & 10.143 \\
\hline
\end{tabular}




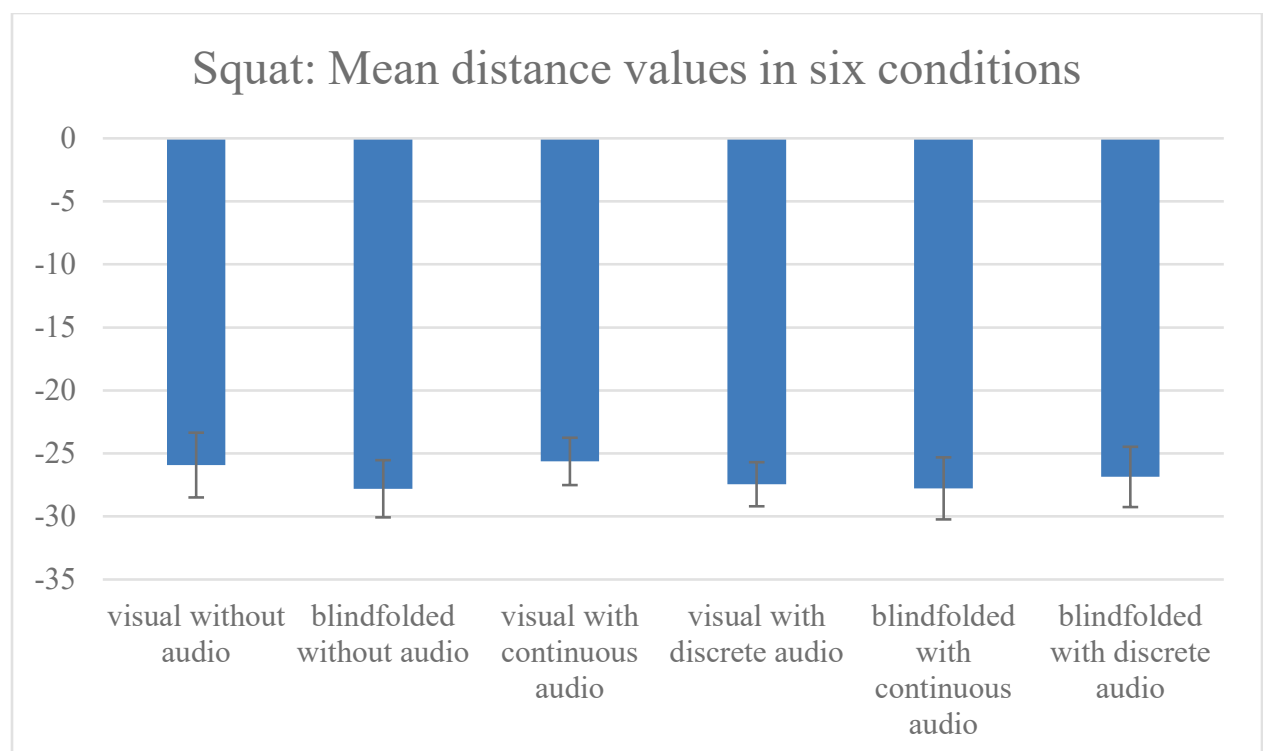

Figure 5.4: Mean distance values in six experimental conditions for squat exercise

The t-test Table 5.4 shows paired samples t-test for the visual without audio condition and the blindfolded with discrete audio condition.

Table 5.4: t-test: Two samples (Visual without audio condition vs blindfolded with discrete audio condition) based on squat exercise

\begin{tabular}{r|c}
\hline & Value \\
\hline degree of freedom & 34 \\
\hline $\mathrm{t}$ stat & 0.269 \\
\hline $\mathrm{p}(\mathrm{T}<=$ two-tail $)$ & 0.79 \\
\hline
\end{tabular}

Paired samples t-test in Table 5.4 between the visual without audio condition (mean=25.92, standard deviation=10.9) and the blindfolded with discrete audio condition (mean $=-26.863$, standard deviation $=10.14$ ) shows no significant differences, $t(34)=$ 0.269 and $p=0.79$. Similarly, for wall sit exercise, Table 5.5 shows the average values and standard deviation of average value data. 
Table 5.5: Average data for wall sit exercise in six experimental conditions

\begin{tabular}{|c|c|c|c|c|c|}
\hline Conditions & Count & Sum & Average & Variance & $\begin{array}{l}\text { Standard } \\
\text { Deviation }\end{array}$ \\
\hline $\begin{array}{l}\text { Visual } \\
\text { without } \\
\text { audio }\end{array}$ & 18 & -498.673 & -27.704 & 52.048 & 7.214 \\
\hline $\begin{array}{l}\text { Blindfolded } \\
\text { without } \\
\text { audio }\end{array}$ & 18 & -454.719 & -25.262 & 45.291 & 6.729 \\
\hline $\begin{array}{l}\text { Visual with } \\
\text { continuous } \\
\text { audio }\end{array}$ & 18 & -492.174 & -27.343 & 98.564 & 9.928 \\
\hline $\begin{array}{l}\text { Visual with } \\
\text { discrete } \\
\text { audio }\end{array}$ & 18 & -491.446 & -27.303 & 52.291 & 7.231 \\
\hline $\begin{array}{l}\text { Blindfolded } \\
\text { with } \\
\text { continuous } \\
\text { audio }\end{array}$ & 18 & -466.774 & -25.932 & 61.291 & 7.829 \\
\hline $\begin{array}{l}\text { Blindfolded } \\
\text { with } \\
\text { discrete } \\
\text { audio }\end{array}$ & 18 & -437.104 & -24.284 & 154.838 & 12.443 \\
\hline
\end{tabular}




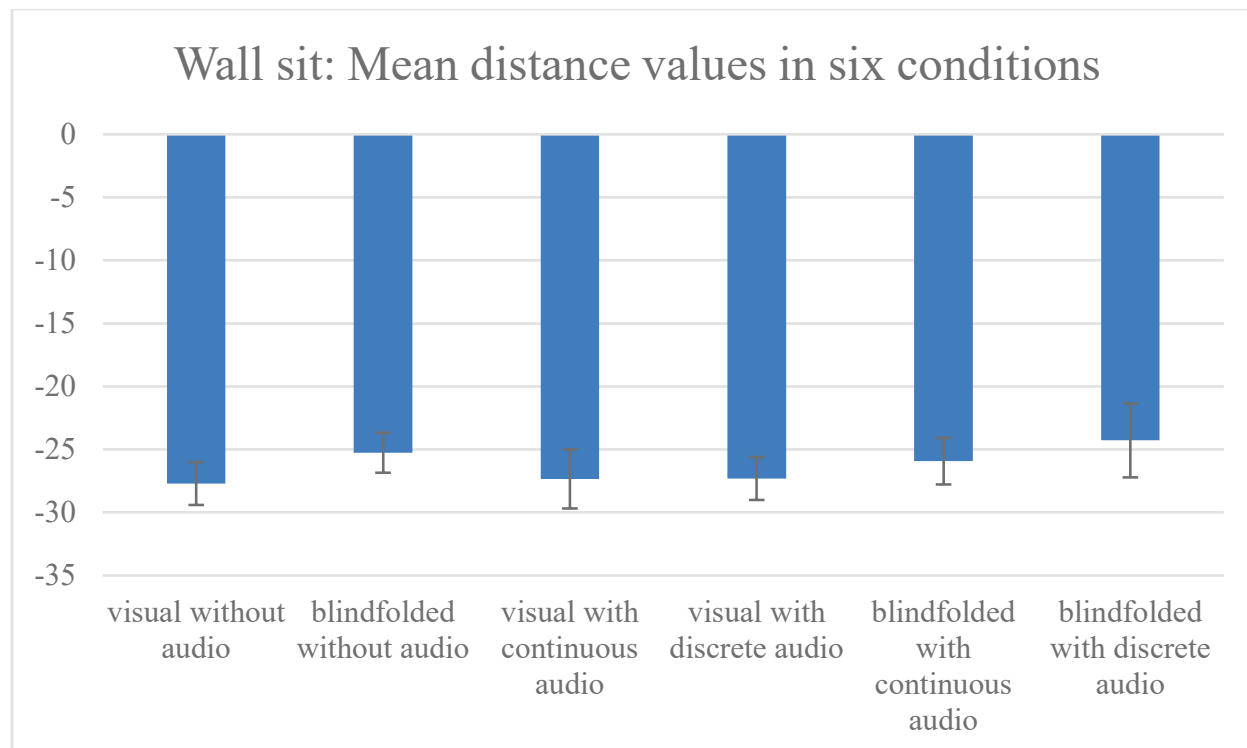

Figure 5.5: Mean distance values in six experimental conditions for wall sit exercise

The t-test Table 5.6 shows paired samples t-test for the visual without audio condition and the blindfolded with discrete audio condition.

Table 5.6: t-test: Two samples (Visual without audio condition vs blindfolded with discrete audio condition) based on wall sit exercise

\begin{tabular}{r|c}
\hline & Value \\
\hline degree of freedom & 27 \\
\hline $\mathrm{t}$ stat & -1.009 \\
\hline $\mathrm{p}(\mathrm{T}<=$ two-tail $)$ & 0.32 \\
\hline
\end{tabular}

The paired samples t-test in Table 5.6 between the visual without audio condition (mean $=-27.7$, standard deviation $=7.2$ ) and the blindfolded with discrete audio (mean=24.28 , standard deviation $=12.44$ ) shows no significant differences, $t(27)=-1.009$ and $p$ $=0.32$. Both of the t-test results suggest that when in the blindfolded with discrete audio condition participants performed not significantly different from the proper form of the exercise compared to the visual without audio condition. In short, in the blindfolded with discrete audio condition, the participants consistently performed the proper form of squat as same as in the visual without audio condition and performed inconsistently but still as good form of wall sit as in the visual without audio condition.

\subsubsection{Effects on completion time}

Musical Exercise calculated the time of an exercise beginning from its start to the end. This is the completion time of the exercise. I wanted to observe if there is any significant difference in time when the same exercise is done for different conditions. Specifically, I wanted to find out if there was any significant difference of completion time during the 
exercises between the visual without audio condition versus the blindfolded with continuous and discrete audio conditions respectively.

Firstly, I checked the squat exercise. Table 5.7 shows the average and standard deviation of all the six conditions for squat exercise in terms of completion time.

Table 5.7: Completion time for squat exercise

\begin{tabular}{|c|c|c|c|c|}
\hline Conditions & Count & Sum & Average & $\begin{array}{l}\text { Standard } \\
\text { Deviation }\end{array}$ \\
\hline $\begin{array}{l}\text { Visual } \\
\text { without } \\
\text { audio }\end{array}$ & 18 & 24195.5 & 1344.194 & 416.354 \\
\hline $\begin{array}{l}\text { Blindfolded } \\
\text { without } \\
\text { audio } \\
\end{array}$ & 18 & 26804 & 1489.111 & 420.739 \\
\hline $\begin{array}{l}\text { Visual with } \\
\text { continuous } \\
\text { audio }\end{array}$ & 18 & 24224 & 1345.778 & 359.749 \\
\hline $\begin{array}{l}\text { Visual with } \\
\text { discrete } \\
\text { audio }\end{array}$ & 18 & 25415.5 & 1411.972 & 291.389 \\
\hline $\begin{array}{l}\text { Blindfolded } \\
\text { with } \\
\text { continuous } \\
\text { audio }\end{array}$ & 18 & 26633.5 & 1479.639 & 473.788 \\
\hline $\begin{array}{l}\text { Blindfolded } \\
\text { with } \\
\text { discrete } \\
\text { audio }\end{array}$ & 18 & 29163.5 & 1620.194 & 553.887 \\
\hline
\end{tabular}

Table 5.8 and Table 5.9 show the t-test results between the visual without audio condition and the blindfolded with two different types of audio (continuous and discrete) conditions for squat exercise. 
Table 5.8: t-test: Two samples (Visual without audio condition vs blindfolded with continuous audio condition) based on squat exercise

\begin{tabular}{r|c}
\hline & Value \\
\hline degree of freedom & 33 \\
\hline $\mathrm{t}$ stat & -0.911 \\
\hline $\mathrm{p}(\mathrm{T}<=$ two-tail $)$ & 0.37 \\
\hline
\end{tabular}

Paired samples t-test in table 5.8 between the visual without audio condition (mean $=1344.19$, standard deviation=416.35) and the blindfolded with continuous audio (mean $=1479.64$, standard deviation $=473.79$ ) for the squat exercise completion time shows no significant differences, $t(33)=-0.91$ and $p=0.37$.

Table 5.9: t-test: Two samples (Visual without audio condition vs blindfolded with discrete audio condition) based on squat exercise

\begin{tabular}{r|c}
\hline & Value \\
\hline degree of freedom & 32 \\
\hline $\mathrm{t}$ stat & -1.69 \\
\hline $\mathrm{p}(\mathrm{T}<=$ two-tail $)$ & 0.10 \\
\hline
\end{tabular}

Paired samples t-test in Table 5.9 between the visual without audio condition (mean=1344.19, standard deviation=416.35) and the blindfolded with discrete audio condition (mean $=1620.19$, standard deviation $=553.89)$ for the squat exercise completion time shows no significant differences, $t(32)=-1.69$ and $p=0.10$.

The above two t-tests in Table 5.8 and in Table 5.9 show that there is no significant difference between the visual without audio condition and the blindfolded with both continuous and discrete audio conditions in terms of squat exercise completion time.

Lastly, I checked the wall sit exercise. Table 5.10 shows the average and standard deviation of all the six conditions for wall sit exercise. 
Table 5.10: Completion time for wall sit exercise

\begin{tabular}{|l|l|l|l|l|}
\hline Conditions & Count & Sum & Average & $\begin{array}{l}\text { Standard } \\
\text { Deviation }\end{array}$ \\
\hline $\begin{array}{l}\text { Visual without } \\
\text { audio }\end{array}$ & 18 & 42659 & 2369.944 & 1216.479 \\
\hline $\begin{array}{l}\text { Blindfolded } \\
\text { without audio }\end{array}$ & 18 & 35747.5 & 1985.972 & 763.947 \\
\hline $\begin{array}{l}\text { Visual with } \\
\text { Continuous } \\
\text { audio }\end{array}$ & 18 & 33814.5 & 1878.583 & 502.788 \\
\hline $\begin{array}{l}\text { Visual with } \\
\text { discrete audio }\end{array}$ & 18 & 45135.5 & 2507.528 & 1031.598 \\
\hline $\begin{array}{l}\text { Blindfolded } \\
\text { with } \\
\text { continuous } \\
\text { audio }\end{array}$ & 18 & & & \\
\hline $\begin{array}{l}\text { Blindfolded } \\
\text { with discrete } \\
\text { audio }\end{array}$ & 18 & 37264 & 2070.222 & 790.649 \\
\hline
\end{tabular}

Table 5.11 and Table 5.12 show the t-test results between the visual without audio condition and the blindfolded with two different types of audio (continuous and discrete) conditions for wall sit exercise.

Table 5.11: t-test: Two samples (Visual without audio condition vs blindfolded with continuous audio condition) based on wall sit exercise

\begin{tabular}{r|c}
\hline & Value \\
\hline degree of freedom & 29 \\
\hline $\mathrm{t}$ stat & 0.876 \\
\hline $\mathrm{p}(\mathrm{T}<=$ two-tail $)$ & 0.39 \\
\hline
\end{tabular}

Paired samples t-test in Table 5.11 between the visual without audio condition (mean=2369.94, standard deviation=1216.49) and the blindfolded with continuous audio condition (mean $=2070.22$, standard deviation $=790.65$ ) for the wall sit exercise completion time shows no significant differences, $t(29)=0.88$ and $p=0.39$. 
Table 5.12: t-test: Two samples (Visual without audio condition vs blindfolded with discrete audio condition) based on wall sit exercise

\begin{tabular}{r|c}
\hline & Value \\
\hline degree of freedom & 33 \\
\hline $\mathrm{t}$ stat & -0.35 \\
\hline $\mathrm{p}(\mathrm{T}<=$ two-tail $)$ & 0.73 \\
\hline
\end{tabular}

Paired samples t-test in Table 5.12 between the visual without audio condition (mean=2369.94, standard deviation=1216.49) and the blindfolded with discrete audio condition $($ mean $=2522.58$, standard deviation=1395.97) for the wall sit exercise completion time shows no significant differences, $t(33)=-0.35$ and $p=0.73$.

Therefore, whether it is squat or wall sit exercise, the exercise completion time is not significantly different in the blindfolded with one of two different audio (continuous and discrete) conditions than in the visual without audio condition. It means that while blindfolded with audios, the participant did not suffer from quickness or lag of completion time compared to a sighted person doing the exercise in the visual without audio condition.

\subsection{Workload Measure}

I used NASA Task Load Index or NASA-TLX as a subjective assessment tool for measuring the perceived workload of Musical Exercise on study participants. After completing each of the six conditions, every participant answered the NASA-TLX questions. Based on their overall ratings of all the six experimental conditions, I conducted paired samples t-tests between the conditions. Table 5.13 shows the average and standard deviation of all the six conditions. 
Table 5.13: Overall rating score of NASA-TLX for six experimental conditions

\begin{tabular}{|l|l|l|l|l|}
\hline Conditions & Count & Sum & Average & $\begin{array}{l}\text { Standard } \\
\text { Deviation }\end{array}$ \\
\hline $\begin{array}{l}\text { Visual without } \\
\text { audio }\end{array}$ & 18 & 639.96 & 35.55 & 18.38 \\
\hline $\begin{array}{l}\text { Blindfolded } \\
\text { without audio }\end{array}$ & 18 & 665.97 & 36.99 & 18.20 \\
\hline $\begin{array}{l}\text { Visual with } \\
\text { continuous } \\
\text { audio }\end{array}$ & 18 & 645.67 & 35.87 & 19.24 \\
\hline $\begin{array}{l}\text { Visual with } \\
\text { discrete audio }\end{array}$ & 18 & 640.98 & 35.61 & 17.71 \\
\hline $\begin{array}{l}\text { Blindfolded } \\
\text { with } \\
\text { continuous } \\
\text { audio }\end{array}$ & 18 & 708.65 & 39.37 & 19.24 \\
\hline $\begin{array}{l}\text { Blindfolded } \\
\text { with discrete } \\
\text { audio }\end{array}$ & 18 & 732.32 & 40.18 & 17.21 \\
\hline
\end{tabular}

Table 5.14 and Table 5.15 show the t-test results between the visual without audio condition and the blindfolded with two different types of audio (discrete and continuous) conditions.

Table 5.14: t-test: Two samples (Visual without audio condition vs blindfolded with continuous audio condition) based on overall rating score of NASA-TLX

\begin{tabular}{r|c}
\hline & Value \\
\hline degree of freedom & 34 \\
\hline $\mathrm{t}$ stat & -0.61 \\
\hline $\mathrm{p}(\mathrm{T}<=$ two-tail $)$ & 0.55 \\
\hline
\end{tabular}

Paired samples t-test in Table 5.14 between visual without audio condition (mean=35.55 , standard deviation=18.38) and blindfolded with continuous audio (mean=39.37, standard deviation $=19.24$ ) shows no significant differences, $t(34)=-0.61$ and $p=0.55$. 
Table 5.15: t-test: Two samples (Visual without audio condition vs blindfolded with discrete audio condition) based on overall rating score of NASA-TLX

\begin{tabular}{r|c}
\hline & Value \\
\hline degree of freedom & 34 \\
\hline $\mathrm{t}$ stat & -0.78 \\
\hline $\mathrm{p}(\mathrm{T}<=$ two-tail $)$ & 0.44 \\
\hline
\end{tabular}

Paired samples t-test in Table 5.15 between the visual without audio condition (mean=35.55, standard deviation $=18.38$ ) and the blindfolded with discrete audio condition (mean $=40.18$, standard deviation $=17.21$ ) shows no significant differences, $t(34)=-0.78$ and $p=0.44$.

The above two t-tests in Table 5.14 and Table 5.15 show that there is no significant difference of overall workload between visual without audio condition and blindfolded with both continuous and discrete conditions in terms of perceived workload measure.

\subsection{Subjective Result}

After all experimental conditions were completed, participants answered the postquestionnaire. "Which sound condition do you like better doing exercise?" with options of with audio or no audio, 14 participants $(77.78 \%$ ) out of 18 participants chose the audio option (either continuous audio or discrete audio). "Which exercise seemed difficult for you?" with options either wall sit or squat, 11 participants $(61.11 \%)$ out of 18 participants answered wall sit. Table 5.16 shows the result of other post questionnaire questions which based on one to five Likert scale where 1 being strongly disagree and 5 being strongly agree.

Table 5.16: Post questionnaire Answers Score

\begin{tabular}{|c|l|l|}
\hline Questions & Average & Standard Deviation \\
\hline $\begin{array}{c}\text { "I think sound was source of information } \\
\text { as feedback for exercise" }\end{array}$ & 4.22 & 0.43 \\
\hline $\begin{array}{c}\text { "The exercise application would improve your } \\
\text { motivation to exercise." }\end{array}$ & 3 & 1.03 \\
\hline $\begin{array}{c}\text { "The exercise application's audio feedback } \\
\text { was intuitive" }\end{array}$ & 3.94 & 0.64 \\
\hline "The exercise application's audio feedback \\
was useful." & & 0.81 \\
\hline
\end{tabular}




\section{Discussion and Recommendations}

In this chapter, I discuss the results from the experimental evaluation of Musical Exercise. At first, I point out the findings from this evaluation. Then, I report if any hypothesis can be supported by the results. Lastly, I lay out the recommendations and design guidelines for systems such as Musical Exercise based on what I found from this study.

\subsection{Discussion}

Musical Exercise is an exercise assistant application for people with visual impairments. My goal was to test if this system is usable and effective for people with visual impairments and if adding audio to the system works as an informative feedback medium. The SUS score of Musical Exercise showed that it is a "above average" or "good" system in terms of usability. For squat the participants in the blindfolded with discrete audio condition tended to show more consistent (i.e., less variance) exercise than in the blindfolded without audio condition in terms of distance values. Also, the paired samples t-test showed that there was no significant difference between the blindfolded with discrete audio condition and the visual without audio condition. Therefore, with this discrete audio, Musical Exercise could improve consistency and assist the participants in maintaining a good form of squat exercise just as a sighted person would do in the visual without audio condition. However, for wall sit exercise, when the participants were in the blindfolded with discrete audio condition, the results were different from the squat case. The performance of the participants was inconsistent both in the blindfolded with discrete audio condition and in the blindfolded with continuous audio condition. The reason seems to lie in participants being blindfolded and doing the wall sit exercise. Firstly, in wall sit exercise, the participants had back support which helped the participants do the exercise. However, in the blindfolded with audio condition, the audio feedback and the physical contact to the wall may conflict with each other or even be combined into ambiguous feedback which might confuse the participants. Secondly, wall sit is a dependent exercise having the back support component, whereas squat is an independent exercise. In squat, the participants developed their own rhythm with the audio feedback and followed it well, but in wall sit, the back support may have hampered the free movement of the participant which might contribute to the bad performance when in the blindfolded with audio conditions. Based on the results of the experiment, using discrete audio feedback can be recommended only for the squat exercise. Further study and validation is needed to improve audio profiles for wall sit. Nonetheless, in both exercises, audio played an important role by maintaining consistency or at least to ensure the proper form of the exercise. Another important factor is that the blindfolded with discrete audio condition has no significant difference with the visual without audio condition in terms of workload measure and completion time. In effect, people could do exercise in the blindfolded with discrete audio condition as good as the visual without audio condition. However, not all audios were helpful. For both wall sit and squat exercises, in the blindfolded with continuous audio condition, the participants performed worse than in the 
blindfolded without audio condition. This result demonstrates that good audio design is crucial because it can assist people with visual impairments perform exercises in a better way. In conclusion, our first two hypotheses are supported in terms of usability and effective exercise assistance system. Between the third and fourth hypotheses, only the third hypothesis (discrete audio) was partly supported by the results.

Though I was unable to run Musical exercise with people with visual impairments, based on the blindfolded conditions, Musical Exercise seems to be promising to be helpful for people with visual impairments. Also, a large portion of the participants $(77.78 \%)$ preferred to do the exercises with audio. They also commented that audio was intuitive and a source of information. Among the audio profiles, some participants liked the discrete audio profile, commenting that it helped "doing exercise in a correct form" or "ending repetition audio is good", etc. Some participants found that "continuous audio was hard to follow or even distracting". Only one participant who had music knowledge commented that continuous audio profile was "more helpful in blindfolded conditions" and "could recognize a pattern in continuous audio". The evaluation of Musical Exercise shows that the participants prefer to do exercise with audio rather than no audio. More importantly, the participants thought that the audio feedback was helpful and informational. What distinguishes Musical Exercise from previous research studies is that the feedback system was intuitive at the same time it was a non-obtrusive form of feedback using audio. Moreover, the use of non-speech audio in Musical Exercise makes it a unique system as the non-speech audio customizes the feedback for the participants. Another feature of Musical Exercise is a non-wearable system which can be used at home environment with less human assistance. However, the Musical Exercise system was evaluated only by blindfolded sighted people. Therefore, Musical Exercise needs to be further evaluated by people with visual impairments.

\subsection{Recommendations for the future systems}

Based on the results, I can make design guidelines or recommendations for systems such as Musical Exercise. Though the discrete audio profile was better perceived by people, at the same time it indicates that further iterative user evaluation is needed. Audio feedback seems to be essential to guide users with visual impairments to do the exercise. It helps them consistently maintain the proper form of exercise. However, it can be done only when the audio is properly designed. More exercises can also be included in the Musical Exercise platform. I can also add some more features to the current exercises (e.g., the degree of inclination of the back). It will require researchers to seek more experts' opinions. Overall, Musical Exercise has room for improvements. 


\section{Conclusion}

Technology is continuously shaping our lives. Using technology in the area of solving accessibility and assistance issues for people seems to be promising. To use technology to its full potential, we need to create a usable and effective system. In the same line, the Musical Exercise platform aims to help people with visual impairments do exercise more independently. I designed the Musical Exercise system and tested it with two different types of audio feedback, compared to no audio condition. It seems that Musical Exercise is promising and heading to the right direction of being an effective and usable system for doing exercises not only for people with visual impairments, but also for sighted people. Adding audio feedback was a unique part of the system. Indeed, real-time audio feedback was crucial to the users so that they could do stable and consistent exercise. It not only worked as a feedback system but also was received positively so that it can also serve as a source of enjoyment during the boring exercises. Most importantly, Musical Exercise is a non-obtrusive system. There is still room for improving the system. I hope that this system can play a major role in the field of using technology for people and guide other similar researchers about how they can design a usable and effective technology. 


\section{Reference List}

[1] Albiol-Pe'rez, S., Lozano-Quilis, J., Gil-Go'mez, H., Gil-Go'mez, J., and Llorens, R. Virtual rehabilitation system for people with parkinsons dis- ease. In 9th international conference on disability, virtual reality and associated technologies (ICDVRAT) (2012), pp. 423-427.

[2] Augestad, L. B., and Jiang, L. Physical activity, physical fitness, and body composition among children and young adults with visual impairments: A systematic review. British Journal of Visual Impairment 33, 3 (2015), 167-182.

[3] Bangor, A., Kortum, P., and Miller, J. Determining what individual sus scores mean: Adding an adjective rating scale. Journal of usability studies 4, 3 (2009), 114-123.

[4] Bolton, J., Lambert, M., Lirette, D., and Unsworth, B. Paperdude: A virtual reality cycling exergame. In CHI '14 Extended Abstracts on Human Factors in Computing Systems (New York, NY, USA, 2014), CHI EA '14, ACM, pp. 475-478.

[5] Buttussi, F., Chittaro, L., and Nadalutti, D. Bringing mobile guides and fitness activities together: A solution based on an embodied virtual trainer. In Proceedings of the 8th Conference on Human-computer Interaction with Mobile Devices and Services (New York, NY, USA, 2006), MobileHCI '06, ACM, pp. 29-36.

[6] Conner, C., and Poor, G. M. Correcting exercise form using body track- ing. In Proceedings of the $2016 \mathrm{CHI}$ Conference Extended Abstracts on Human Factors in Computing Systems (New York, NY, USA, 2016), CHI EA '16, ACM, pp. 3028-3034.

[7] Elliott, D., Carr, S., and Orme, D. The effect of motivational music on submaximal exercise. European Journal of Sport Science 5, 2 (2005), 97-106.

[8] Fletcher, G. F., Balady, G., Blair, S. N., Blumenthal, J., Caspersen, C., Chaitman, B., Epstein, S., Froelicher, E. S. S., Froelicher, V. F., Pina, I. L., et al. Statement on exercise: benefits and recommendations for physical activity programs for all Americans. Circulation 94, 4 (1996), 857-862.

[9] Ganesan, S., and Anthony, L. Using the kinect to encourage older adults to exercise: A prototype. In CHI '12 Extended Abstracts on Human Factors in Computing Systems (New York, NY, USA, 2012), CHI EA '12, ACM, pp. 2297- 2302.

[10] Gerling, K. M., Kalyn, M. R., and Mandryk, R. L. Kinectwheels: Wheelchairaccessible motion-based game interaction. In CHI '13 Extended Ab- stracts on Human Factors in Computing Systems (New York, NY, USA, 2013), CHI EA '13, ACM, pp. 3055-3058. 
[11] Gowin, M., Cheney, M., Gwin, S., and Wann, T. F. Health and fitness app use in college students: A qualitative study. American Journal of Health Education 46, 4 (2015), 223-230.

[12] Houwen, S., Hartman, E., and Visscher, C. Physical activity and motor skills in children with and without visual impairments. Medicine and science in sports and exercise 41, 1 (2009), 103-109.

[13] Huang, M.-C., Chen, E., Xu, W., and Sarrafzadeh, M. Gaming for up- per extremities rehabilitation. In Proceedings of the $2 \mathrm{Nd}$ Conference on Wireless Health (New York, NY, USA, 2011), WH '11, ACM, pp. 27:1-27:2.

[14] Jacko, J. A., Scott, I. U., Sainfort, F., Barnard, L., Edwards, P. J., Emery, V. K., Kongnakorn, T., Moloney, K. P., and Zorich, B. S. Older adults and visual impairment: What do exposure times and accuracy tell us about performance gains associated with multimodal feedback? In Proceedings of the SIGCHI Conference on Human Factors in Computing Systems (New York, NY, USA, 2003), CHI '03, ACM, pp. 33-40.

[15] Kasim, P. Optimizing squat technique. Strength and Conditioning Journal 29, 6 (2007), 10.

[16] Laukka, P., and Quick, L. Emotional and motivational uses of music in sports and exercise: A questionnaire study among athletes. Psychology of Music 41, 2 (2013), 198-215.

[17] Lin, T.-Y., Hsieh, C.-H., and Lee, J.-D. A kinect-based system for phys- ical rehabilitation: Utilizing tai chi exercises to improve movement disorders in patients with balance ability. In Proceedings of the 2013 7th Asia Modelling Symposium (Washington, DC, USA, 2013), AMS '13, IEEE Computer Society, pp. 149-153.

[18] Middelweerd, A., Mollee, J. S., van der Wal, C. N., Brug, J., and te Velde, S. J. Apps to promote physical activity among adults: a review and content analysis.

International Journal of Behavioral Nutrition and Physical Activity 11, 1 (2014), 1-9.

[19] Morelli, T., Foley, J., Columna, L., Lieberman, L., and Folmer, E. Vi-tennis: A vibrotactile/audio exergame for players who are visually im- paired. In Proceedings of the Fifth International Conference on the Foundations of Digital Games (New York, NY, USA, 2010), FDG '10, ACM, pp. 147-154.

[20] Muehlbradt, A., Koushik, V., and Kane, S. K. Goby: A wearable swimming aid for blind athletes. In Proceedings of the 19th International ACM SIGACCESS Conference on Computers and Accessibility (New York, NY, USA, 2017), ASSETS '17, ACM, pp. 377-378. 
[21] Newbold, J. W., Bianchi-Berthouze, N., Gold, N. E., Tajadura- Jime'nez, A., and Williams, A. C. Musically informed sonification for chronic pain rehabilitation: Facilitating progress \&\#38; avoiding over-doing. In Proceed- ings of the $2016 \mathrm{CHI}$ Conference on Human Factors in Computing Systems (New York, NY, USA, 2016), CHI '16, ACM, pp. 5698-5703.

[22] Palacios-Navarro, G., Garc'ia-Magarin o, I., and Ramos-Lorente, P. A kinectbased system for lower limb rehabilitation in parkinson's disease pa- tients: a pilot study. Journal of Medical Systems 39, 9 (2015), 103.

[23] Rector, K., Bennett, C. L., and Kientz, J. A. Eyes-free yoga: An exergame using depth cameras for blind \&\#38; low vision exercise. In Proceed- ings of the 15th International ACM SIGACCESS Conference on Computers and Accessibility (New York, NY, USA, 2013), ASSETS '13, ACM, pp. 12:1-12:8.

[24] Salmon, P. Effects of physical exercise on anxiety, depression, and sensitivity to stress: a unifying theory. Clinical psychology review 21, 1 (2001), 33-61.

[25] Shapiro, D. R., Moffett, A., Lieberman, L., and Dummer, G. M. Perceived competence of children with visual impairments. Journal of Visual Impairment \& Blindness 99, 1 (2005), 15.

[26] Singh, A., Klapper, A., Jia, J., Fidalgo, A., Tajadura-Jime'nez, A., Kanakam, N., Bianchi-Berthouze, N., and Williams, A. Motivating people with chronic pain to do physical activity: Opportunities for technology design. In Proceedings of the SIGCHI Conference on Human Factors in Com- puting Systems (New York, NY, USA, 2014), CHI '14, ACM, pp. 2803-2812.

[27] Taylor, D. Physical activity is medicine for older adults. Postgraduate Medical Journal 90, 1059 (2014), 26-32.

[28] Wang, Q., Turaga, P., Coleman, G., and Ingalls, T. Somatech: An ex- ploratory interface for altering movement habits. In Proceedings of the Extended Abstracts of the $32 \mathrm{Nd}$ Annual ACM Conference on Human Factors in Computing Systems (New York, NY, USA, 2014), CHI EA '14, ACM, pp. 1765-1770.

[29] Warburton, D. E., Nicol, C. W., and Bredin, S. S. Health benefits of physical activity: the evidence. Canadian Medical Association Journal 174, 6 (2006), 801-809.

[30] Weil, E., Wachterman, M., McCarthy, E. P., Davis, R. B., O’day, B., Iezzoni, L. I., and Wee, C. C. Obesity among adults with disabling conditions. Jama 288, 10 (2002), $1265-1268$. 
[31] Winoto, P., and Tang, T. Y. Sensory substitution to enable the visually impaired to play an affordable wearable mobile game. In Adjunct Proceedings of the 2015 ACM International Joint Conference on Pervasive and Ubiquitous Com- puting and Proceedings of the 2015 ACM International Symposium on Wearable Computers (New York, NY, USA, 2015), UbiComp/ISWC'15 Adjunct, ACM, pp. 193-196.

[32] Zayer, M. A., Tregillus, S., Bhandari, J., Feil-Seifer, D., and Folmer, E. Exploring the use of a drone to guide blind runners. In International ACM SIGACCESS Conference on Computers and Accessibility (Reno, NV, October 2016), pp. 263-264.

[33] Keppel, G., and Wicken, T. D. Design and analysis: A researcher's handbook. London, UK: Pearson Prentice Hall. (2004).

[34] Nadia Kanwal, Erkan Bostanci, Keith Currie, and Adrian F. Clark, "A Navigation System for the Visually Impaired: A Fusion of Vision and Depth Sensor," Applied Bionics and Biomechanics, vol. 2015, Article ID 479857, 16 pages, 2015. doi:10.1155/2015/479857

[35] Moll, Jonas, and Eva-Lotta Sallnäs. "Communicative functions of haptic feedback." In International Conference on Haptic and Audio Interaction Design, pp. 1-10. Springer, Berlin, Heidelberg, 2009. 


\section{A Pre-questionnaire}

1. Age:

2. Sex

$\dagger$ Male

$\dagger$ Female

3. Occupation

4. Height: $\mathrm{ft}$ in

5. Weight: $1 b$

Genral Health Questions: Please check the box to indicate your answer for each question. If you answer yes to any of the following seven questions (question

no. 6 to 12), you will not be allowed to participate in the study FOR YOUR SAFETY. 
6. Has your doctor ever said that you have a heart condition OR high blood pressure?

$\dagger$ YES

$\dagger \mathrm{NO}$

7. Do you feel pain in your chest at rest, during your daily activities of living, OR when you do physical activity?

$\dagger$ YES

$\dagger \mathrm{NO}$

8. Do you lose balance because of dizziness OR have you lost consciousness in the last 12 months? Please answer NO if your dizziness was associated with over-breathing (including during vigorous exercise).

$\dagger \mathrm{YES}$

$\dagger \mathrm{NO}$ 
9. Have you ever been diagnosed with another chronic medical condition (other than heart disease or high blood pressure)?

$\dagger$ YES

$\dagger \mathrm{NO}$

10. Are you currently taking prescribed medications for a chronic medical condition?

$\dagger$ YES

$\uparrow \mathrm{NO}$

11. Do you have a bone or joint problem that could be made worse by becoming more physically active? Please answer NO if you had a joint problem in the past, but it does not limit your current ability to be physically active. For example, knee, ankle, shoulder or other.

$\dagger$ YES

$\dagger \mathrm{NO}$ 
12. . Has your doctor ever said that you should only do medically supervised physical activity?

$\dagger$ YES

$\dagger \mathrm{NO}$

Other questions:

13. How many times in a week do you exercise?

$\dagger$ Everyday

$\dagger 5-6$ times

$\dagger$ 3-4 times

$\dagger 1-2$ times

$\dagger$ Never

14. If you do exercise what kind of exercise do you do? 
$\uparrow$ Bodyweigth exercise

$\dagger$ Barbell/Dumbbell/Kettlebell/Machine exercise

$\uparrow$ Cardio

$\uparrow$ Yoga

$\dagger$ Others:

15. Have you heard about Squat?

$\uparrow$ Never

$\dagger$ Yes, heard about it

$\dagger$ I know how to do it

$\dagger$ I do it sometimes 
$\dagger$ I do it regularly

16. Have you heard about Lunge?

$\dagger$ Never

$\dagger$ Yes, heard about it

$\dagger$ I know how to do it

$\dagger$ I do it sometimes

$\dagger$ I do it regularly

17. Do you want to exercise regularly for better well-being?

$\dagger$ Yes

$\dagger$ No 
18. Will you use technological assistance while you are doing exercise like logging information of how much exercise you have done so far or how the exercise is going?

$\dagger$ Yes

$\dagger$ No

19. Have you used any application for doing exercise e.g. any mobile applications?

$\dagger$ Yes

$\dagger$ No 


\section{B Post-questionnaire}

System Usability Scale:

1. I think that I would like to use this system frequently

(1) Strongly Disagree (2) Disagree (3) Neutral (4) Agree (5) Strongly Agree

2. I found the system unnecessarily complex

(1) Strongly Disagree (2) Disagree (3) Neutral (4) Agree (5) Strongly Agree

3. I thought the system was easy to use

(1) Strongly Disagree (2) Disagree (3) Neutral (4) Agree (5) Strongly Agree

4. I think that I would need the support of a technical person to be able to use this system

(1) Strongly Disagree (2) Disagree (3) Neutral (4) Agree (5) Strongly Agree

5. I found the various functions in this system were well integrated

(1) Strongly Disagree (2) Disagree (3) Neutral (4) Agree (5) Strongly Agree

6. I thought there was too much inconsistency in this system

(1) Strongly Disagree (2) Disagree (3) Neutral (4) Agree (5) Strongly Agree

7. I would imagine that most people would learn to use this system very quickly 
(1) Strongly Disagree (2) Disagree (3) Neutral (4) Agree (5) Strongly Agree

8. I found the system very cumbersome to use

(1) Strongly Disagree (2) Disagree (3) Neutral (4) Agree (5) Strongly Agree

9. I felt very confident using the system

(1) Strongly Disagree (2) Disagree (3) Neutral (4) Agree (5) Strongly Agree

10. I needed to learn a lot of things before I could get going with this system

(1) Strongly Disagree (2) Disagree (3) Neutral (4) Agree (5) Strongly Agree

Other Questions:

1. In which of the following condition do you like better doing exercise?

a) With sound

b) Without sound

2. Which of the following exercises seemed difficult for you?(you can choose multiple answers).
a) Squat
b) Lunge
c) Wall sit 
3. I think the sound helped in doing the exercise?

(1) Strongly Disagree (2) Disagree (3) Neutral (4) Agree (5) Strongly Agree

4. I think the sound was a source of information as feedback for exercise?

(1) Strongly Disagree (2) Disagree (3) Neutral (4) Agree (5) Strongly Agree

5. Have you used this kind of sensors (or exercise application) before?
a)Yes
b)No

6. This exercise application cause interests to work out.

(1) Strongly Disagree (2) Disagree (3) Neutral (4) Agree (5) Strongly Agree

7. This exercise application would improve your motivation to exercise.

(1) Strongly Disagree (2) Disagree (3) Neutral (4) Agree (5) Strongly Agree

8. This exercise application would be helpful to improve your lower body strength.

(1) Strongly Disagree (2) Disagree (3) Neutral (4) Agree (5) Strongly Agree

9. This exercise application would be helpful to improve your cognitive function.

(1) Strongly Disagree (2) Disagree (3) Neutral (4) Agree (5) Strongly Agree

10. The exercise application's visual feedback was intuitive.

(1) Strongly Disagree (2) Disagree (3) Neutral (4) Agree (5) Strongly Agree

11. The exercise application's visual feedback was useful.

(1) Strongly Disagree (2) Disagree (3) Neutral (4) Agree (5) Strongly Agree

12. The exercise application's visual feedback was appropriate for the given tasks.

(1) Strongly Disagree (2) Disagree (3) Neutral (4) Agree (5) Strongly Agree

13. The exercise application's audio feedback was intuitive. 
(1) Strongly Disagree (2) Disagree (3) Neutral (4) Agree (5) Strongly Agree

14. The exercise application's audio feedback was useful.

(1) Strongly Disagree (2) Disagree (3) Neutral (4) Agree (5) Strongly Agree

15. The exercise application's audio feedback was appropriate for the given tasks.

(1) Strongly Disagree (2) Disagree (3) Neutral (4) Agree (5) Strongly Agree

s16. In general, what components of an exercise application are most important? (Choose top 3)

(1) Accessibility

(6) Contents

(11) Safety

(2) Exercise enhancement

(7) Convenience

(12) Durability

(3) Fun

(8) Intelligence

(13) Performance

(4) Design

(9) Interaction with other devices

(5) Functionality

(10) Communication with social media

17. Is there anything (including functionality, design) you would like us to improve with this exercise application?

\section{(}

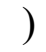

Thank you. If you have a question, let us know. 


\section{NASA-TLX}

NASA-TLX questionnaire (same set of questions after completing an experimental condition)

Two screenshots of NASA-TLX questionnaire-

Task Questionnire - Pant 1

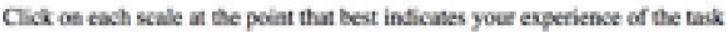

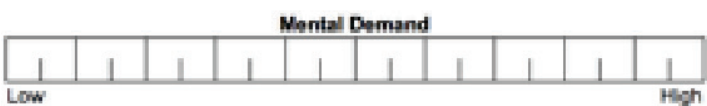

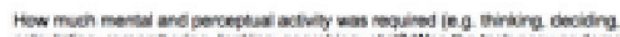

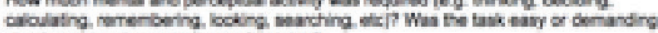

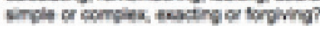

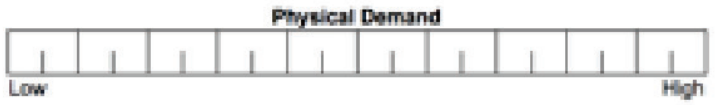

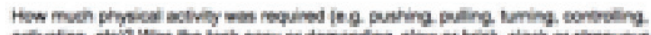

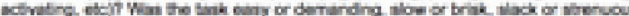
motu or laberew?

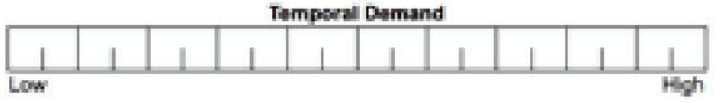

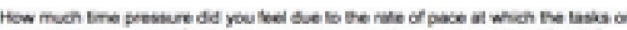

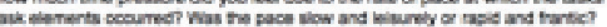

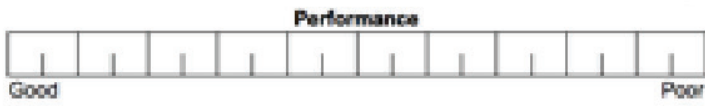

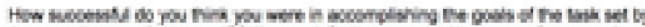

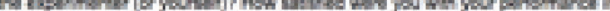
cocomplating these pois?

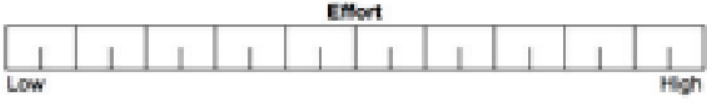

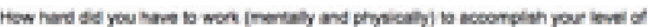
pertomanow?

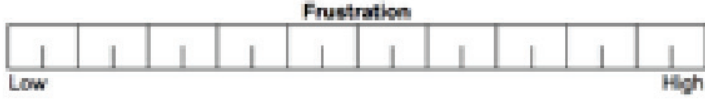

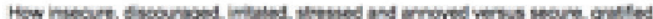

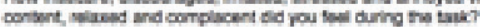

Task Questionnaire - Part 2

Click on the factor that represents the more important contributor to workload for the task

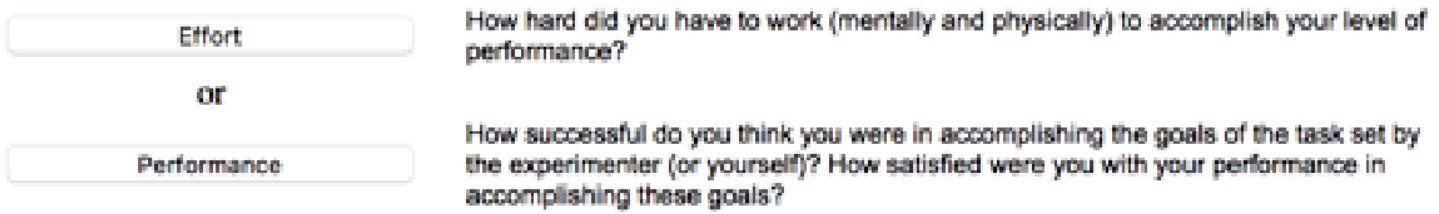

Source URL: http://www.keithv.com/software/nasatlx/

Online tool at the above source URL:

http://www.keithv.com/software/nasatlx/nasatlx.html 